\title{
Automated Programmable Generation of Broad pH Range Volatile Ionic Eluents for Liquid Chromatography
}

Charles Phillip Shelor ${ }^{1}$, Kenji Yoshikawa, Purnendu K. Dasgupta*

Department of Chemistry and Biochemistry, University of Texas at Arlington, Arlington, Texas 76019-0065, United States.

\section{Supporting Information}

Table of Content

Table S1.xlsx Results of computational simulation. Excel table separately uploaded.

Constants used in numerical simulation $\quad$ S3

Figure S1. pH Contour plot of mixing respective solutions equilibrated with $\mathrm{CO}_{2}$ and $\mathrm{NH}_{3} \quad \mathrm{~S} 4$

Figure S2. Buffer intensity for system of Figure S1 S5

Figure S3. pH Surface for data in Figure $3 \quad$ S6

$\begin{array}{ll}\text { Figure S4. Buffer intensity surface for data in Figure } 3 & \text { S7 }\end{array}$

Figure S5. Same as Figure S3 except solvent A is $20 \mathrm{mM} \mathrm{HOAc} \quad$ S8

Figure S6. Buffer intensity surface for data in Figure S5 S9

Figure S7. System and control schematic for ammonia engasser. $\quad$ S10

Figure S8. Ammonia permeation rate measurement by direct conductometry S11

Figure S9. Ammonia permeation rate measurement by conductometric titration $\quad \mathrm{S} 12$

Figure S10. Ammonia permeation rate dependence on engasser length S13

Figure S11. Conductance based on $\lambda^{0}$ values vs. ionic strength $\quad$ S14

Figure S12. unsuccessful attempts to separate chiral isomers of NEA S15

Figure S13. Chiral separation of several racemic primary amines S16

Figure S14. Total and extracted ion chromatograms, anion exchange separation of amino acids $\quad$ S17

Figure S15. Apparatus for permeative introduction of acetic acid $\quad$ S19

Figure S16. Alternate Apparatus for permeative introduction of acetic acid $\quad$ S20

Figure S17. Effect of donor pressure on permeated concentration of acetic acid $\quad$ S21

Figure S18. Effect of donor pressure on $\mathrm{AcOH}$ permeation at different temperatures $\quad \mathrm{S} 22$

Figure S19. Total and extracted ion chromatograms, cation exchange separation of amino acids S23

More on amino acid separations on Hitachi columns. $\quad$ S24

\footnotetext{
${ }^{1}$ Corresponding authors. Email address: $\underline{\text { Shelor@uta.edu, use dasgupta@uta.edu }}$
} 
Figure S20. Complete separation of 16 amino acids, Hitachi PF column, $30^{\circ} \mathrm{C} \quad \mathrm{S} 25$

Figure S21. Incomplete separation of 19 amino acids, Hitachi PF column, $50{ }^{\circ} \mathrm{C} \quad \mathrm{S} 26$

$\begin{array}{ll}\text { Figure S22. Same as Figure } \mathrm{S} 21,65^{\circ} \mathrm{C} & \mathrm{S} 27\end{array}$

Figure S23. Higher $\mathrm{pNH}_{3}$ allows elution of histidine $\quad$ S28

Table S2. Enthalpy of Partition for Selected Amino acids $\quad$ S29

Figure S24. Using a 2-step $\mathrm{pNH}_{3}$ gradient and a temperature program to enhance separation $\quad$ S30

Figure S25. Mass spectrum of lactalbumin with charge state attribution in the present system S31

Figure S26. Mass spectrum of lactalbumin with charge state attribution in the present system S32

Figure S27. Mass spectrum of ubiquitin with charge state attribution in the present system S33

Figure S28. Mass spectrum of bovine cytochrome $c$ with charge state attribution in present system S34

Figure S29. Mass spectrum of equine cytochrome $c$ with charge state attribution in present system S35

Figure S30. Complete chromatogram and gradient program for Figure 11 bottom S36 
Constants Used in Numerical Simulations (all at 298K)

Henry's Law constant for $\mathrm{CO}_{2} 0.037$ M/atm Reference S1

Henry's Law constant for $\mathrm{NH}_{3} 55.96$ M/atm Reference S2

Acid Dissociation Constant of $\mathrm{H}_{2} \mathrm{CO}_{3}{ }^{*} 4.27 \times 10^{-7} \quad$ Reference S3

Acid Dissociation Constant of $\mathrm{HCO}_{3}{ }^{-} 4.68 \times 10^{-11} \quad$ Reference S4

Acid Dissociation Constant of $\mathrm{NH}_{4}^{+} 5.62 \times 10^{-10} \quad$ Reference S5 


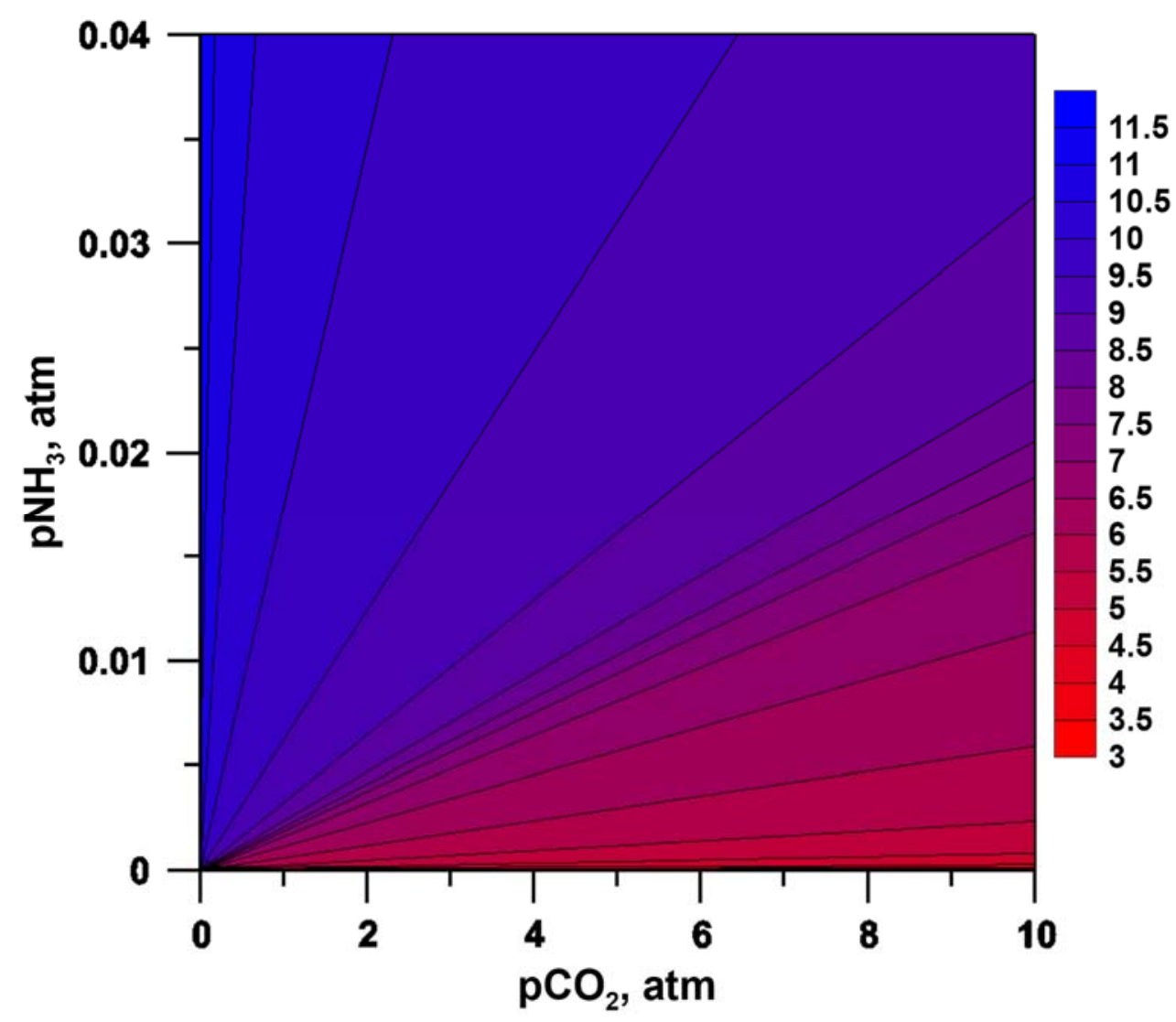

Figure S1. Contour plot for $\mathrm{pH}$ of a mixture generated by mixing two solutions, one equilibrated with $\mathrm{CO}_{2}$ and the other with $\mathrm{NH}_{3}$ (both gases in the indicated pressure ranges), then mixed in a 3:1 volumetric ratio in the indicated order. 


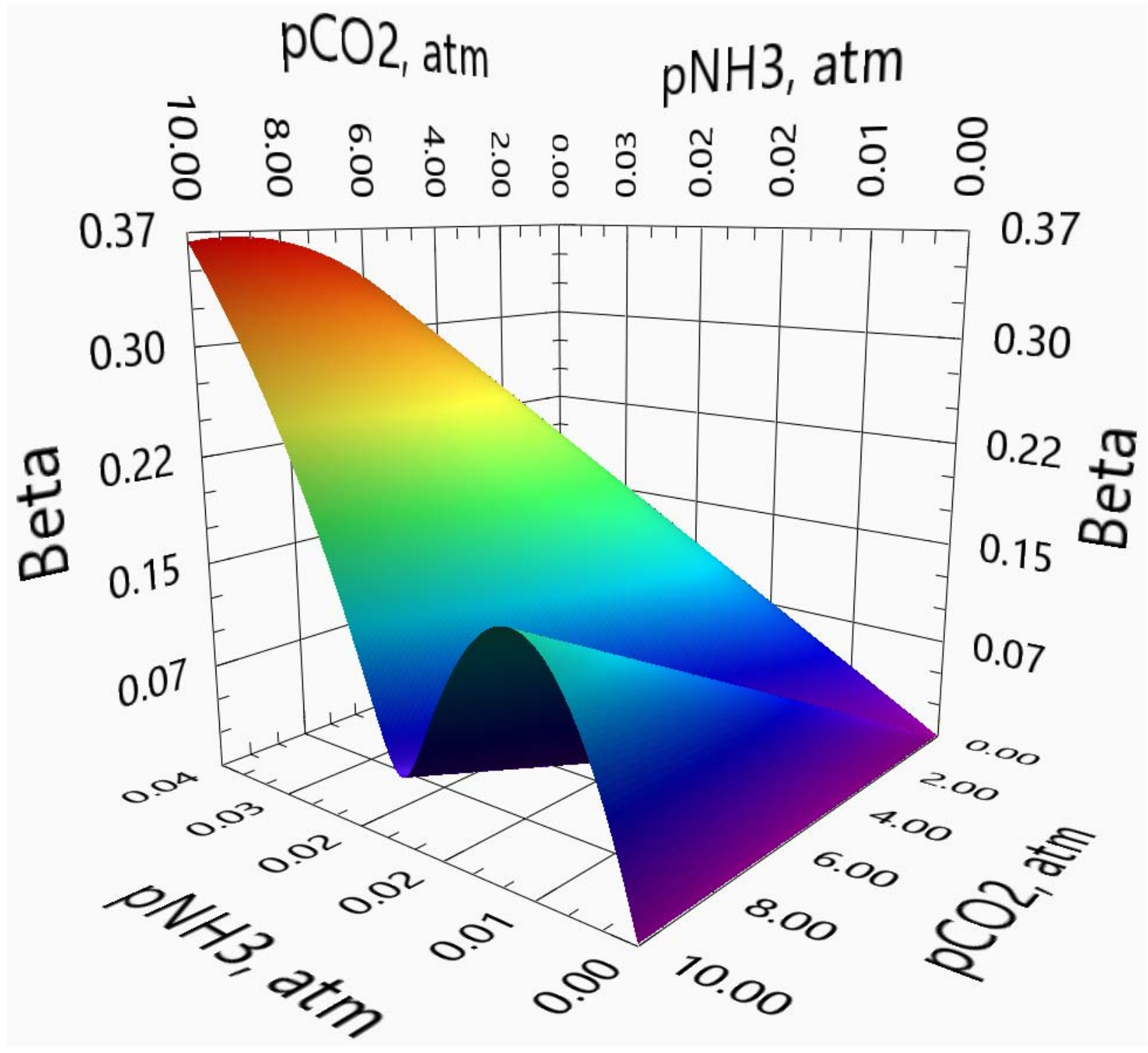

Figure S2. The buffer intensity in $\mathrm{M} / \mathrm{pH}$ unit for the system in Figure S1. 


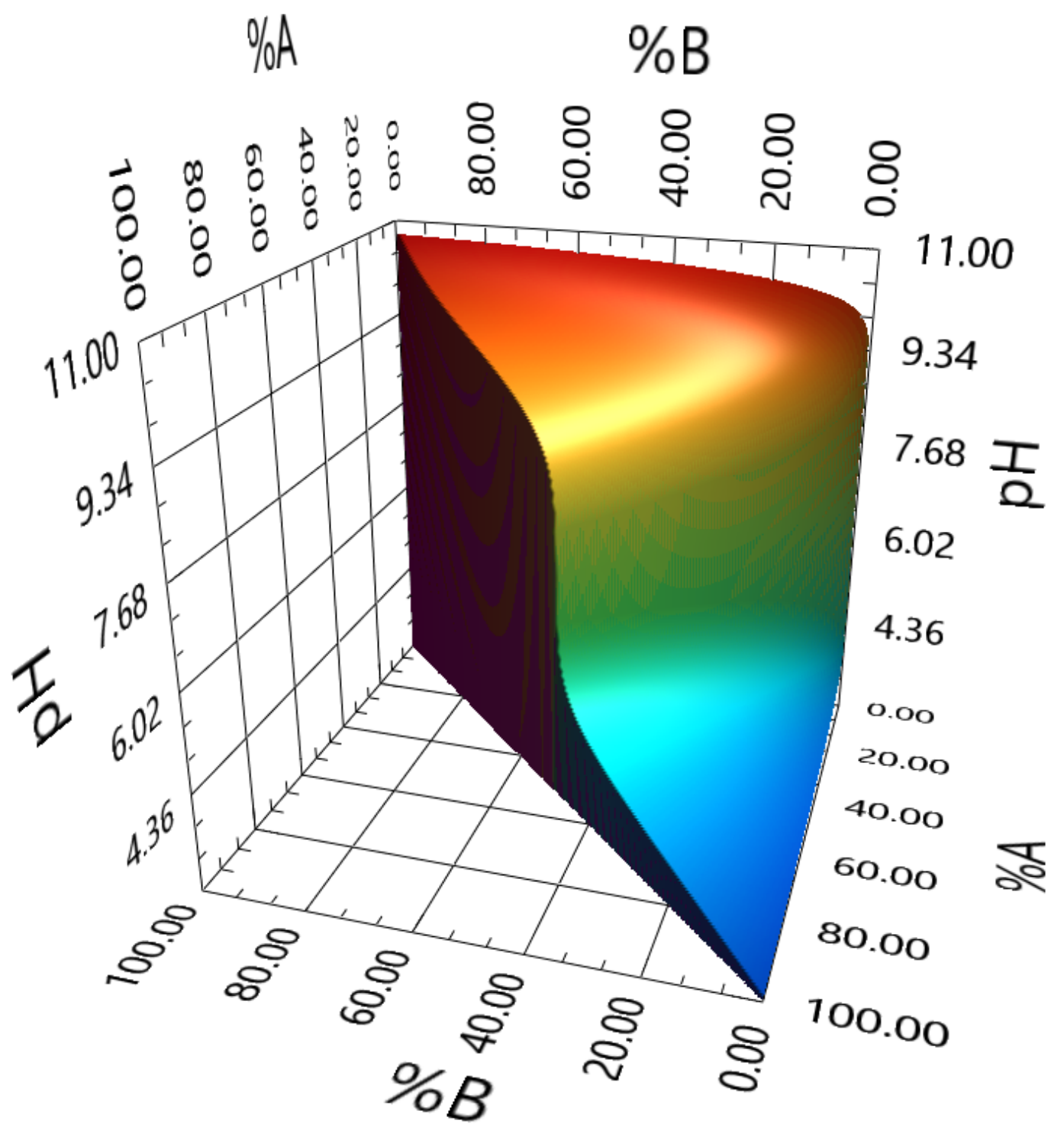

Figure S3. $\mathrm{pH}$ surface for the data in Figure 3 at any possible concentrations of $\mathrm{A}$ (20 $\mathrm{mM} \mathrm{HCOOH})$ and $\mathrm{B}\left(20 \mathrm{mM} \mathrm{NH}_{4} \mathrm{OH}\right)$. The edge of the surface corresponds to the $\mathrm{pH}$ line in Figure 3. 


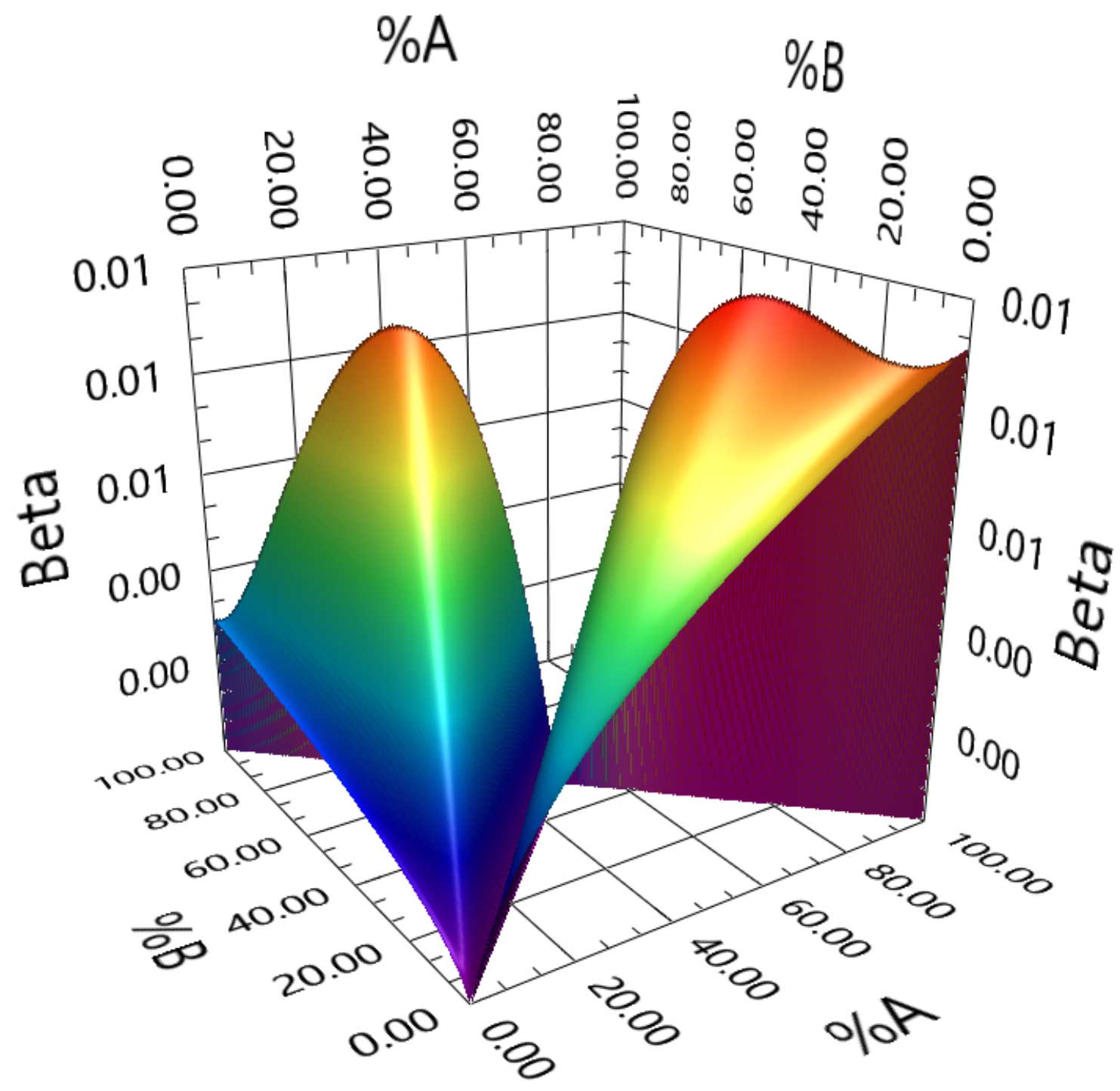

Figure S4. $\beta$ surface for the data in Figure 3 at any possible concentrations of $A$ (20 $\mathrm{mM} \mathrm{HCOOH})$ and $\mathrm{B}\left(20 \mathrm{mM} \mathrm{NH}_{4} \mathrm{OH}\right)$. 


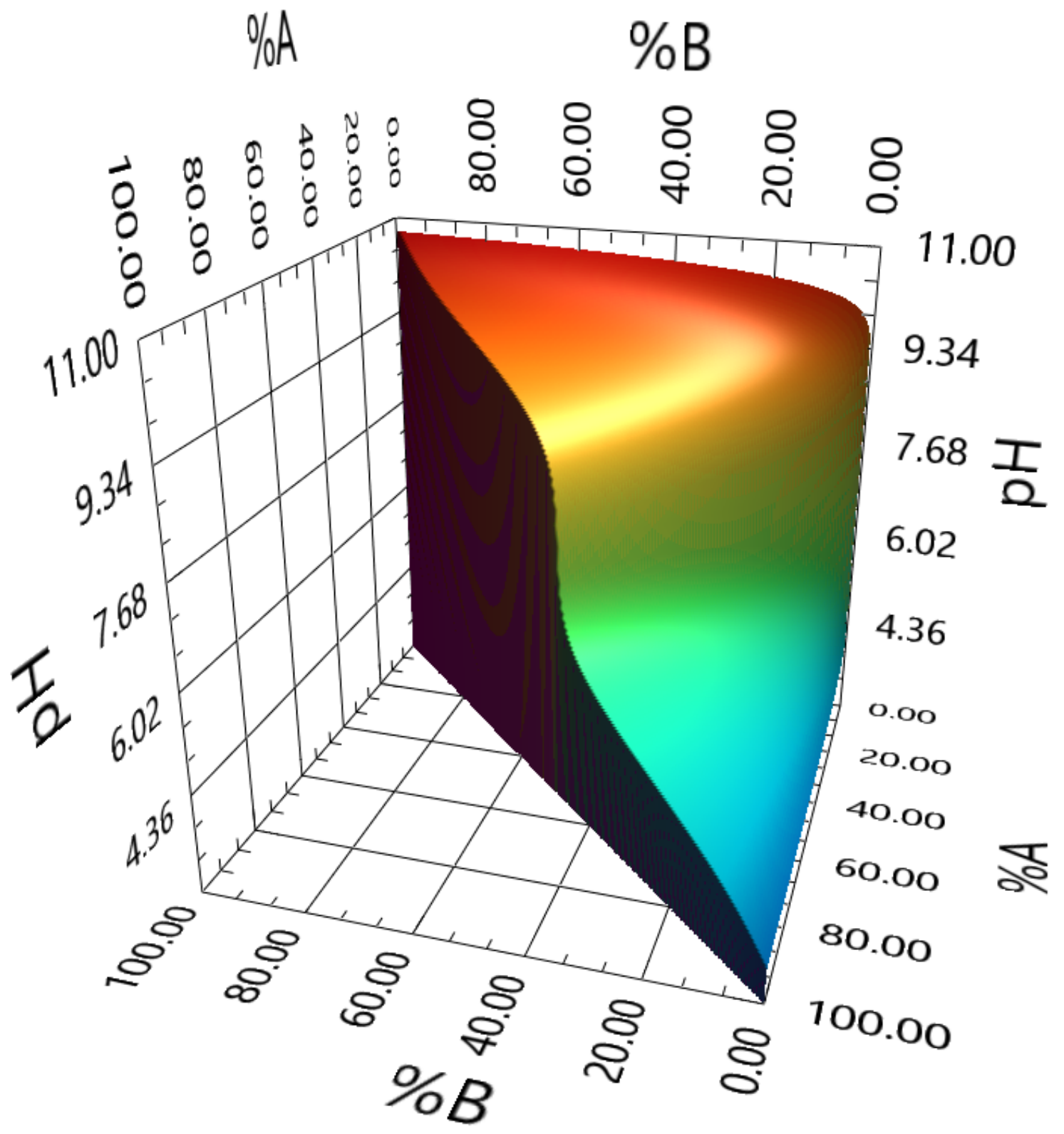

Figure S5. Same as Figure S3 except solvent $A$ is $20 \mathrm{mM} \mathrm{HOAc}$ 


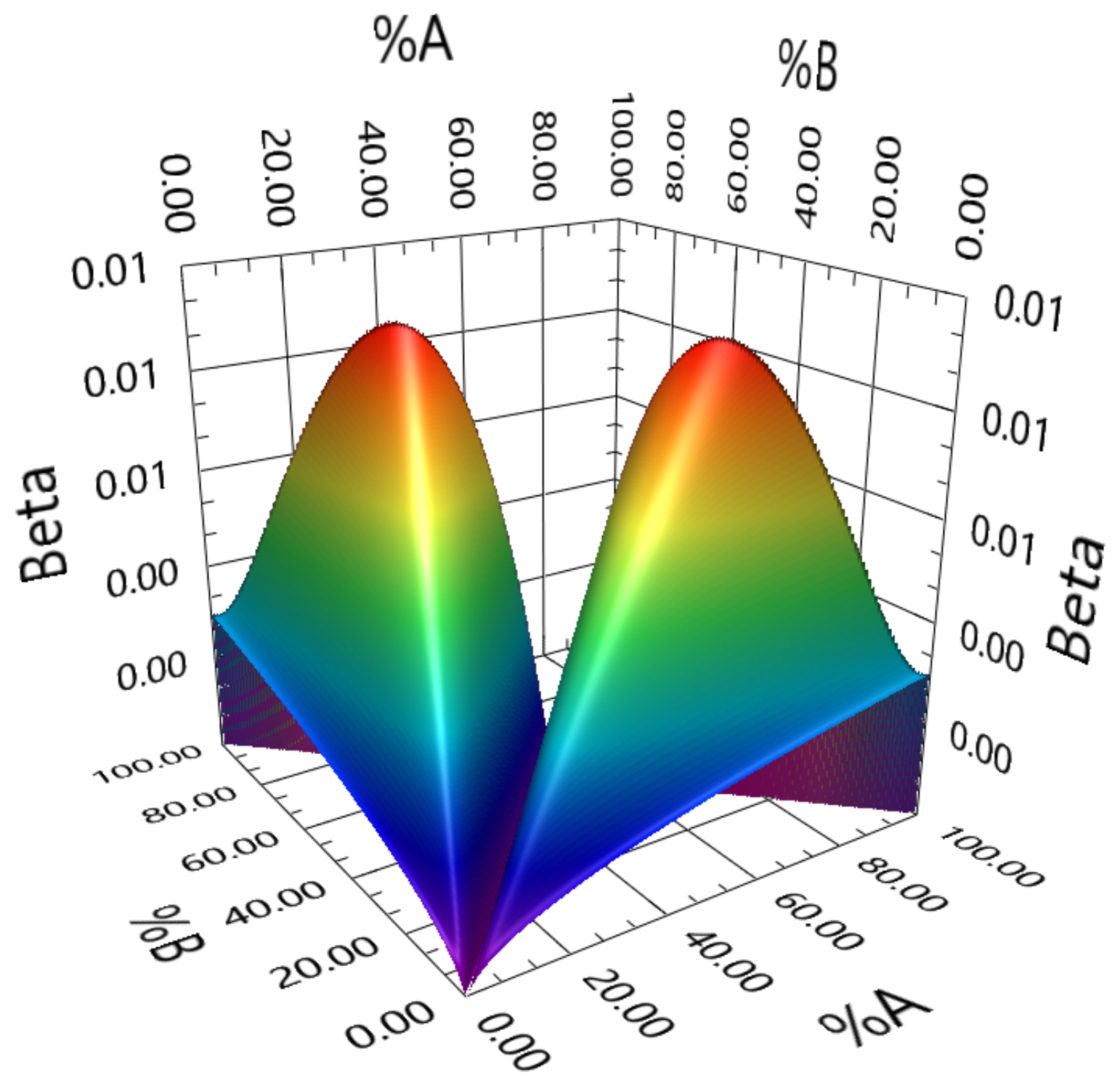

Figure S6. $\beta$ surface for the data in Figure S5. 


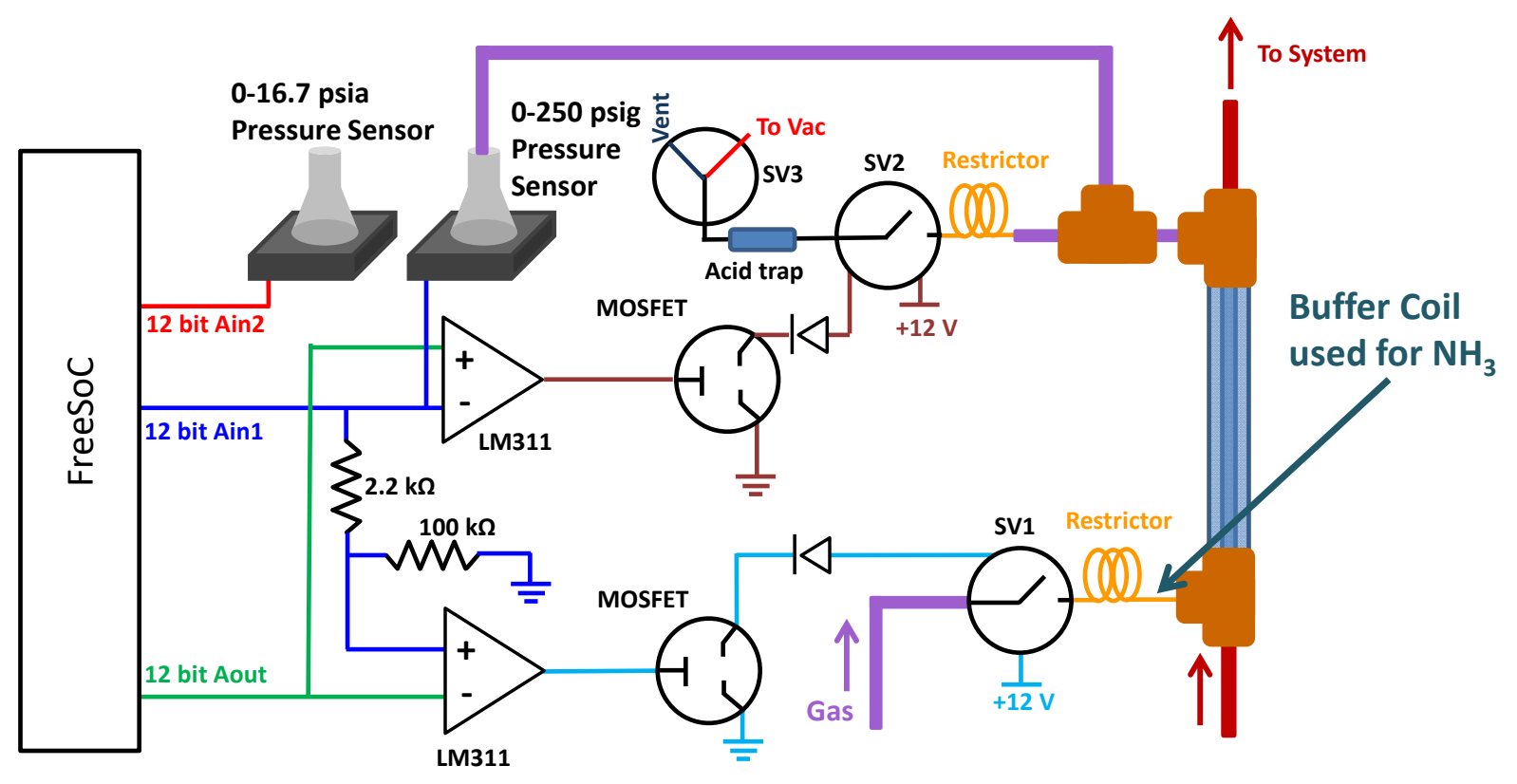

Figure S7. System and control schematic for ammonia engasser. A similar control system is used for the $\mathrm{CO} 2$ engasser. The microcontroller used was the Freesoc implementation (https://www.sparkfun.com/products/13714) of the PSoC5LP programmable system on a chip (https://www.cypress.com/products/32-bit-arm-cortexm3-psoc-5lp). The device was configured to acquire data for all the pressure sensors and the high-pressure conductivity cell, as well to supply analog outputs to control the pressure. The pressure was controlled using two comparators (LM311), 2 MOSFETs (IRF630), and 2 solenoid valves (SV1,2, www.peterpaul.com, see text). For ammonia a further 3-way solenoid valve (SV3) was needed and driven in the same manner. The analog output from the FreeSoC was directly coupled to both comparators but on opposite inputs. The output of the high-pressure sensor (these read gage pressure and not absolute) was wired to the other terminals of the comparator and was also recorded with 12-bit precision by the FreeSoC. It was important to step the voltage down to the input of the comparator that controls the source valve to prevent continuous venting and filling. When the comparator output goes low (input to the + input less than that to the input), the MOSFET energizes the SV. Capillary restrictors (see text) reduce the introduction flow rate, otherwise the engasser pressure immediately requires venting. Similarly, silica capillary restrictors are used to prevent immediate re-pressurization. Since permeation ultimately depends on the absolute pressure and not the gauge pressure, an ambient sensor is used to monitor and continuously correct for any changes in ambient pressure. 


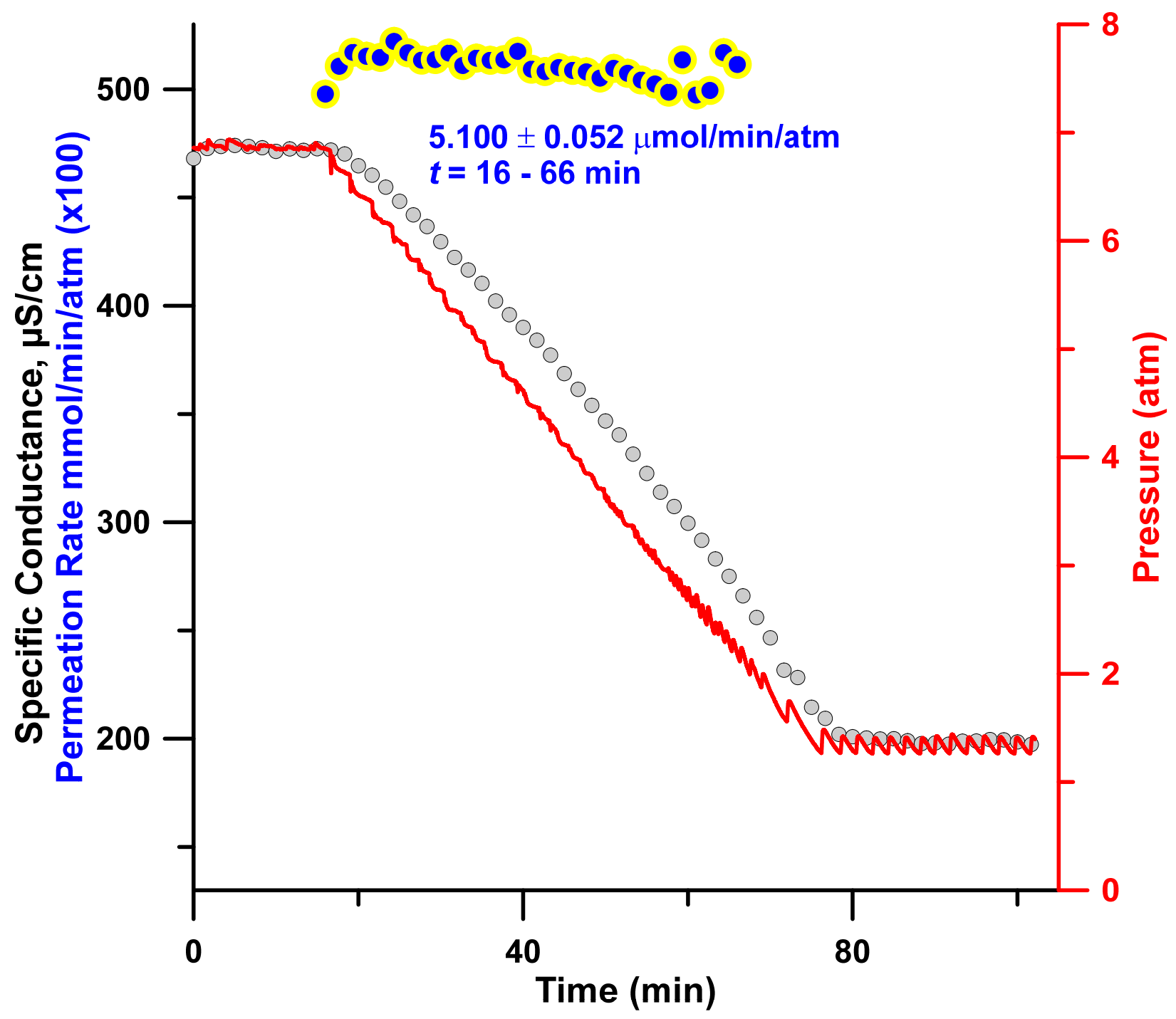

Figure S8. Direct conductometric measurement of ammonia permeation rate of a $40 \mathrm{~cm}$ long engasser. The light gray circles are the conductance data which is essentially $\mathrm{C}\left(\lambda_{\mathrm{NH} 4_{+}}+\lambda_{\mathrm{OH}}\right)$. From the known values of $\lambda_{\mathrm{NH} 4+}$ and $\lambda_{\mathrm{OH}}$, , one can compute $\mathrm{C}=\left[\mathrm{NH}_{4}{ }^{+}\right]=$ $\left[\mathrm{OH}^{-}\right]$. A knowledge of $\left[\mathrm{OH}^{-}\right]$gives $\left[\mathrm{H}^{+}\right]$via $\mathrm{K}_{\mathrm{w}} . \mathrm{A}$ knowledge of $\left[\mathrm{H}^{+}\right],\left[\mathrm{NH}_{4}^{+}\right]$, and $\mathrm{K}_{\mathrm{a}} \mathrm{NH}_{4}$ then provides $\left[\mathrm{NH}_{3}\right]$ and hence $\mathrm{N}_{\mathrm{T}}\left(=\left[\mathrm{NH}_{4}{ }^{+}\right]+\left[\mathrm{NH}_{3}+\right]\right) .1000 \mathrm{NTF}$ is the permeation rate in $\mu \mathrm{mol} / \mathrm{min}$ where $F$ is the influent flow rate of water into the engasser $(0.2 \mathrm{~mL} / \mathrm{min})$. One calculates the permeation rate per unit applied $\mathrm{pNH}_{3}$ by dividing by $\mathrm{pNH}_{3}$. 


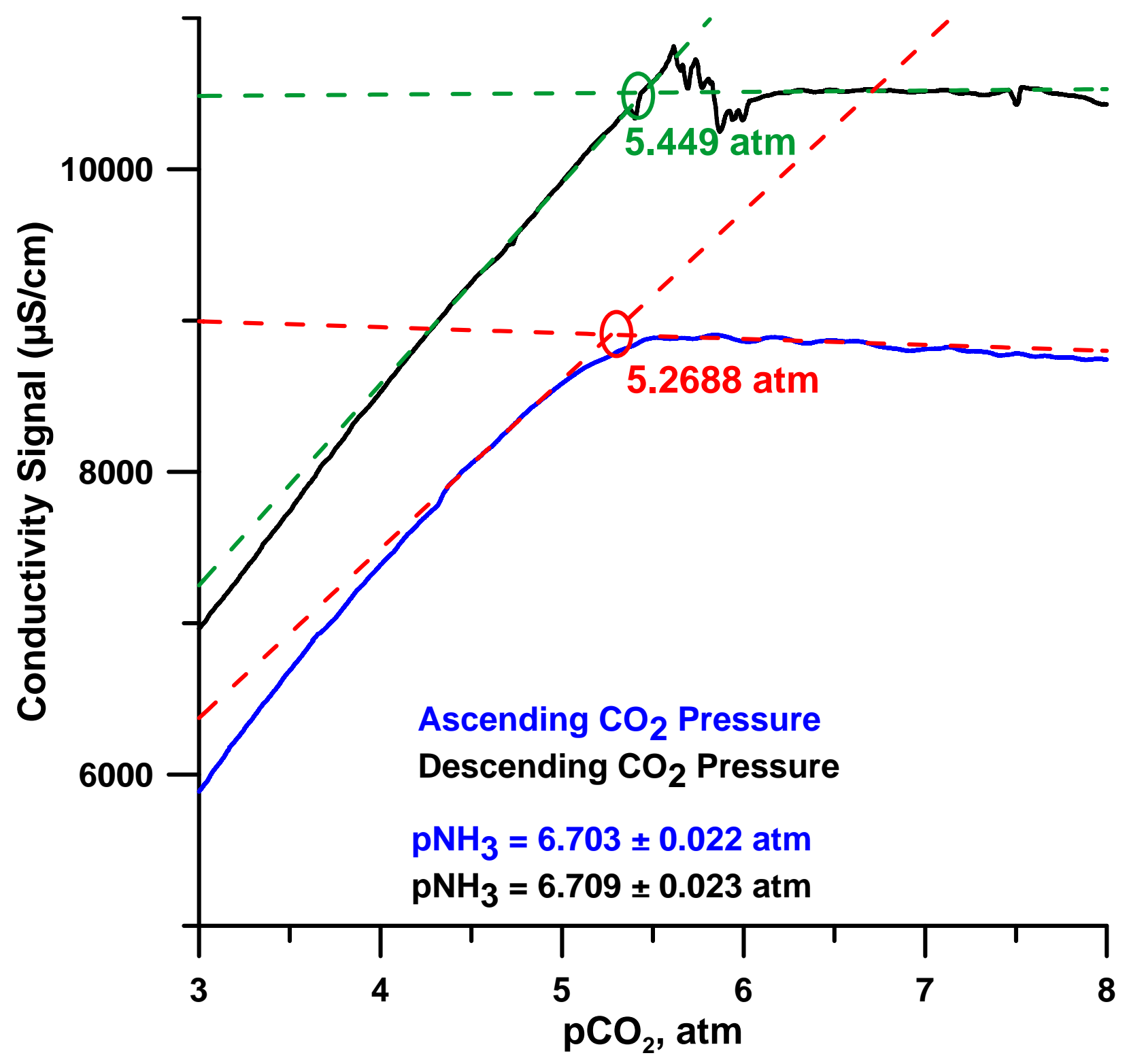

Figure S9. $\mathrm{CO}_{2}$ permeation rate determination at constant $\mathrm{pNH}_{3}$ by titration with varying $\mathrm{CO}_{2}$ pressure. Both ascending and descending $\mathrm{pCO}_{2}$ data are shown. The sloping part of the trace represents the conversion of $\mathrm{NH}_{4} \mathrm{OH}$ to $\left(\mathrm{NH}_{4}\right)_{2} \mathrm{CO}_{3}$. Once $\left(\mathrm{NH}_{4}\right)_{2} \mathrm{CO}_{3}$ begins to be converted to $\mathrm{NH}_{4} \mathrm{HCO}_{3}$ (nearly flat portion of the trace), there is very little change in conductance. The end point is determined from extrapolating each linear portion, as standard in conductometric titrations. Engasser lengths: $\mathrm{CO}_{2}: 42 \mathrm{~cm}, \mathrm{NH}_{3}: 25 \mathrm{~cm}$. The $\mathrm{NH}_{3}$ engasser had permeation rate of $3.41 \pm 0.02 \mu \mathrm{mol} / \mathrm{min} / \mathrm{atm} ; \mathrm{CO}_{2}$ as determined from the above titration was $4.26 \pm 0.07 \mu \mathrm{mol} / \mathrm{min} / \mathrm{atm}$. 


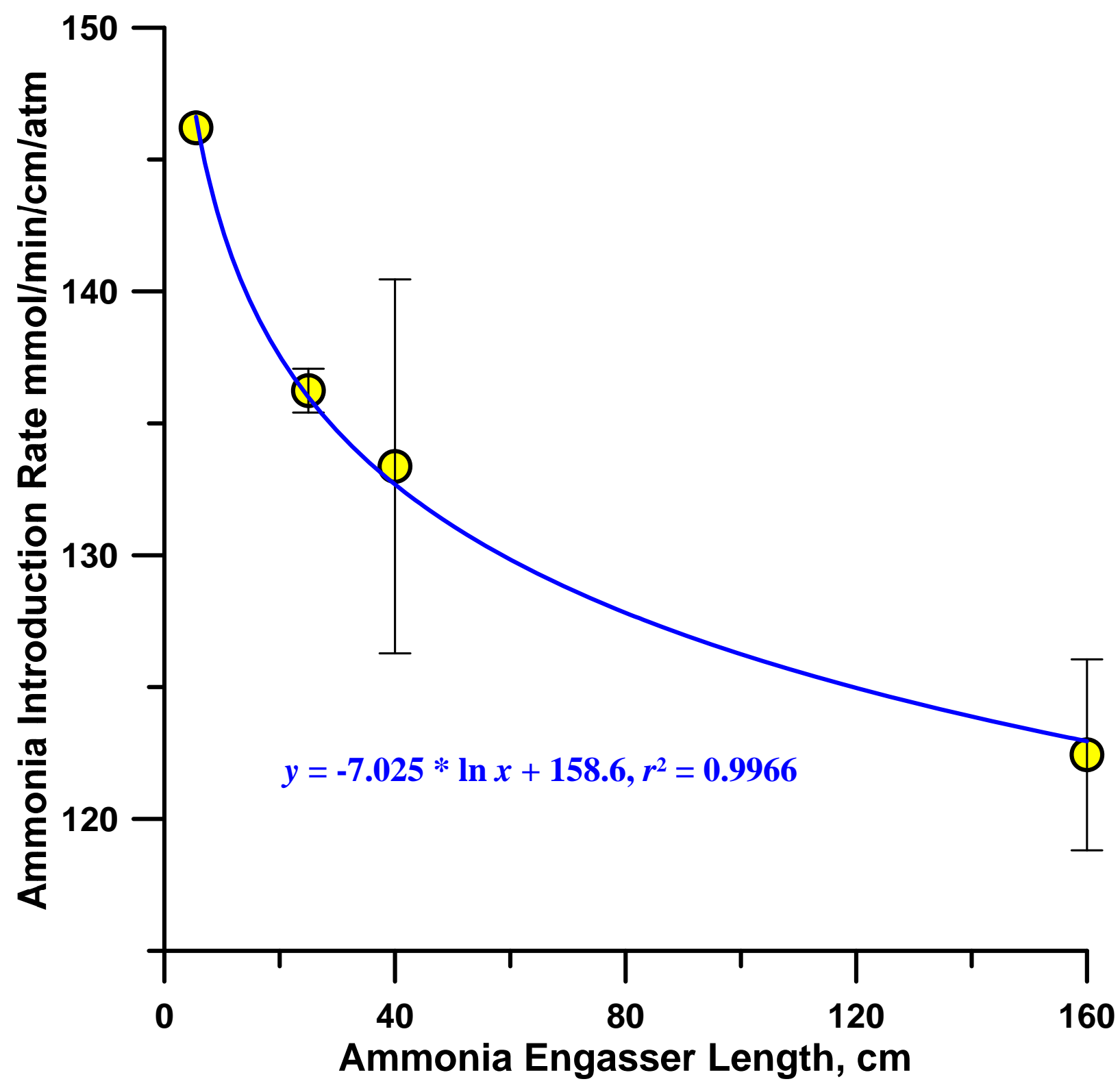

Figure S10. Permeation rate per unit length determined for ammonia. The majority of the values were determined by direct conductometry at constant $\mathrm{pNH}_{3}$; two of the three $160 \mathrm{~cm}$ results were determined by titration with known concentration of $\mathrm{HNO}_{3}(108.7 \pm$ $0.94 \mathrm{mM}$ ), itself standardized by titration with primary standard $\mathrm{Na}_{2} \mathrm{CO}_{3}$ solution. 


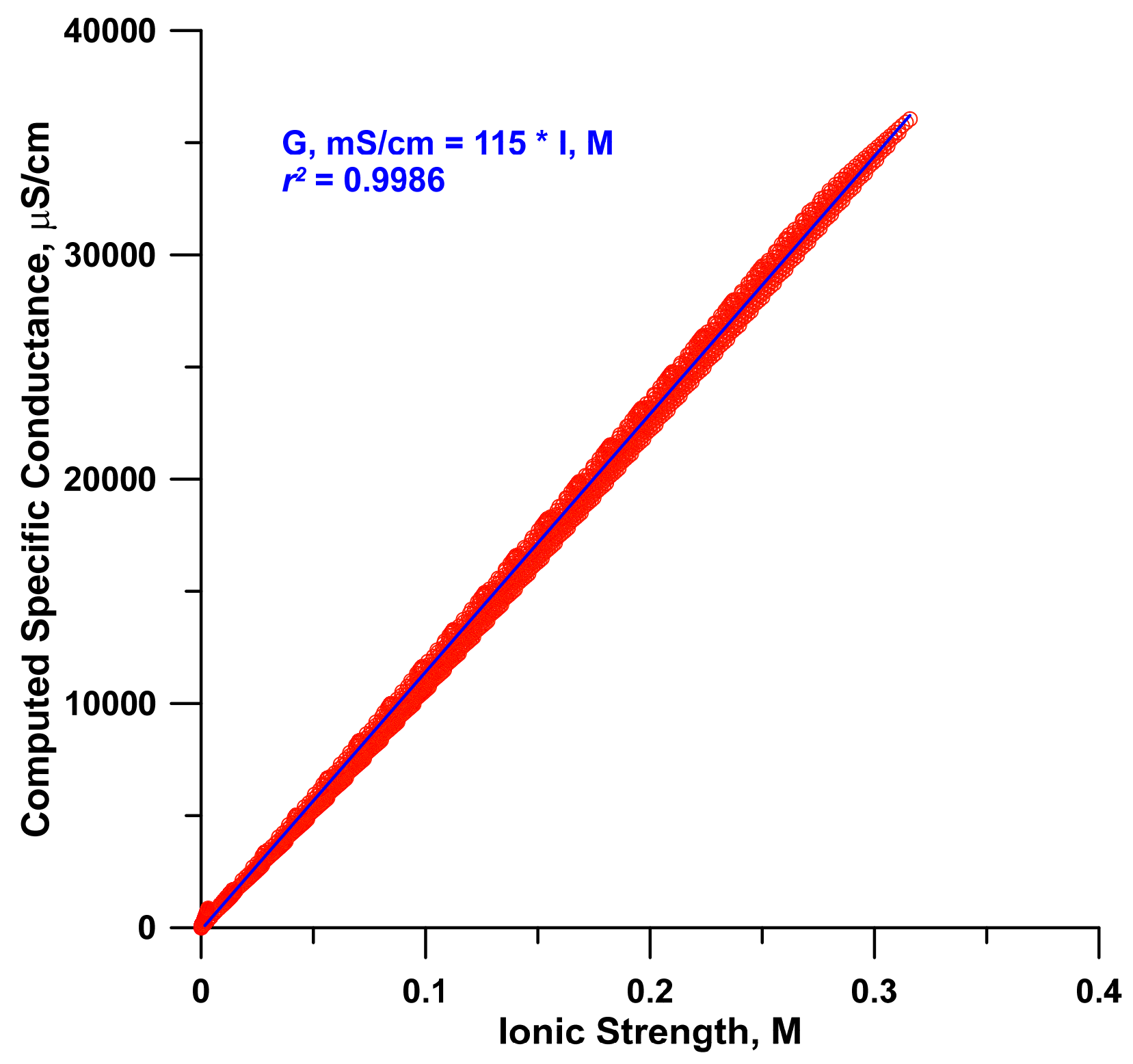

Figure S11. Conductivity was computed in Table S1, using all the ions present and their infinite dilution equivalent conductance values. This is plotted as a function of the computed ionic strength $(I)$. The slope is very close to the sum of $\lambda^{0} \mathrm{NH}_{4+}(73.5)$ and $\lambda^{0} \mathrm{HCO}_{3}$ (44.5), indicating the dominance of $\mathrm{NH}_{4}{ }^{+}$and $\mathrm{HCO}_{3}{ }^{-}$as current carriers over the bulk of the considered range. In reality at concentrations much above $10 \mathrm{mM}$, the actual equivalent conductance will increasingly be lower than $\lambda^{0}$ values and the conductance will increasingly be more linearly related to $\sqrt{ } I$, see ref. S6. 


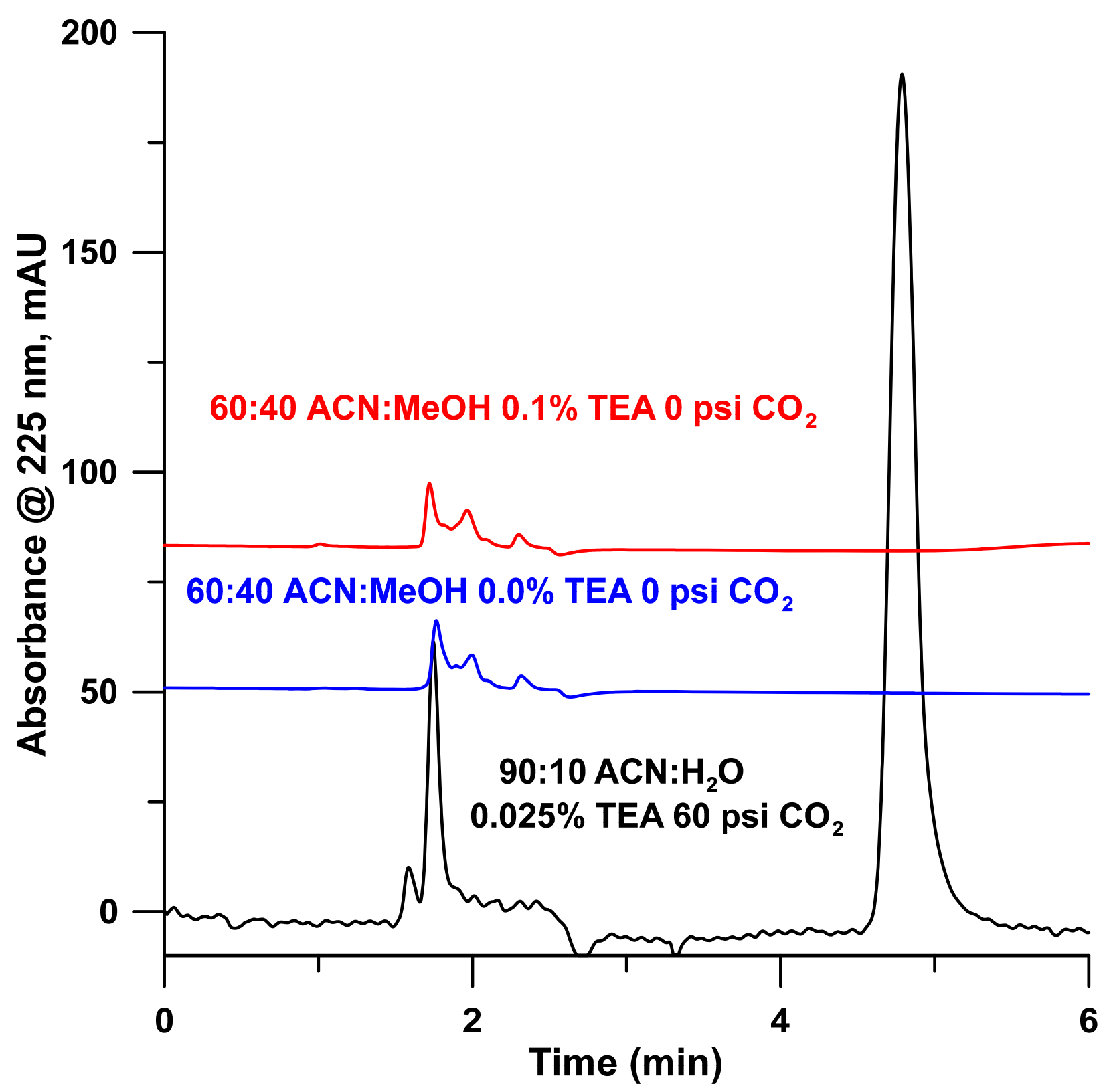

Figure S12. Unsuccessful separation attempts to resolve 1-(1-Naphthyl)ethylamine on a $4.6 \times 150 \mathrm{~mm}$ isopropyl derivatized cyclofructan bonded phase on a fully porous $5 \mu \mathrm{m}$ fully porous silica phase (LARIHC CF6-P). No $\mathrm{CO}_{2}$ was added to the polar organic mobile phase in the top two traces: in the red vs the blue trace, $0.1 \%$ TEA was present and absent, respectively. Both TEA and $\mathrm{CO}_{2}$ need to be present for separation to occur (see Figure $5^{*}$ ). However, although TEA and $\mathrm{CO}_{2}$ may both be present in a watercontaining high ACN, HILIC like eluent, there is retention but no chiral selectivity.

${ }^{*}$ In Figure 5, one phenomenon not understood is that the peak areas are not conserved as the TEA levels are varied. Consistently, some of the injected solute appear as the unresolved peak pair but the rest of it appears as a broad hump afterwards, especially at higher TEA levels. 


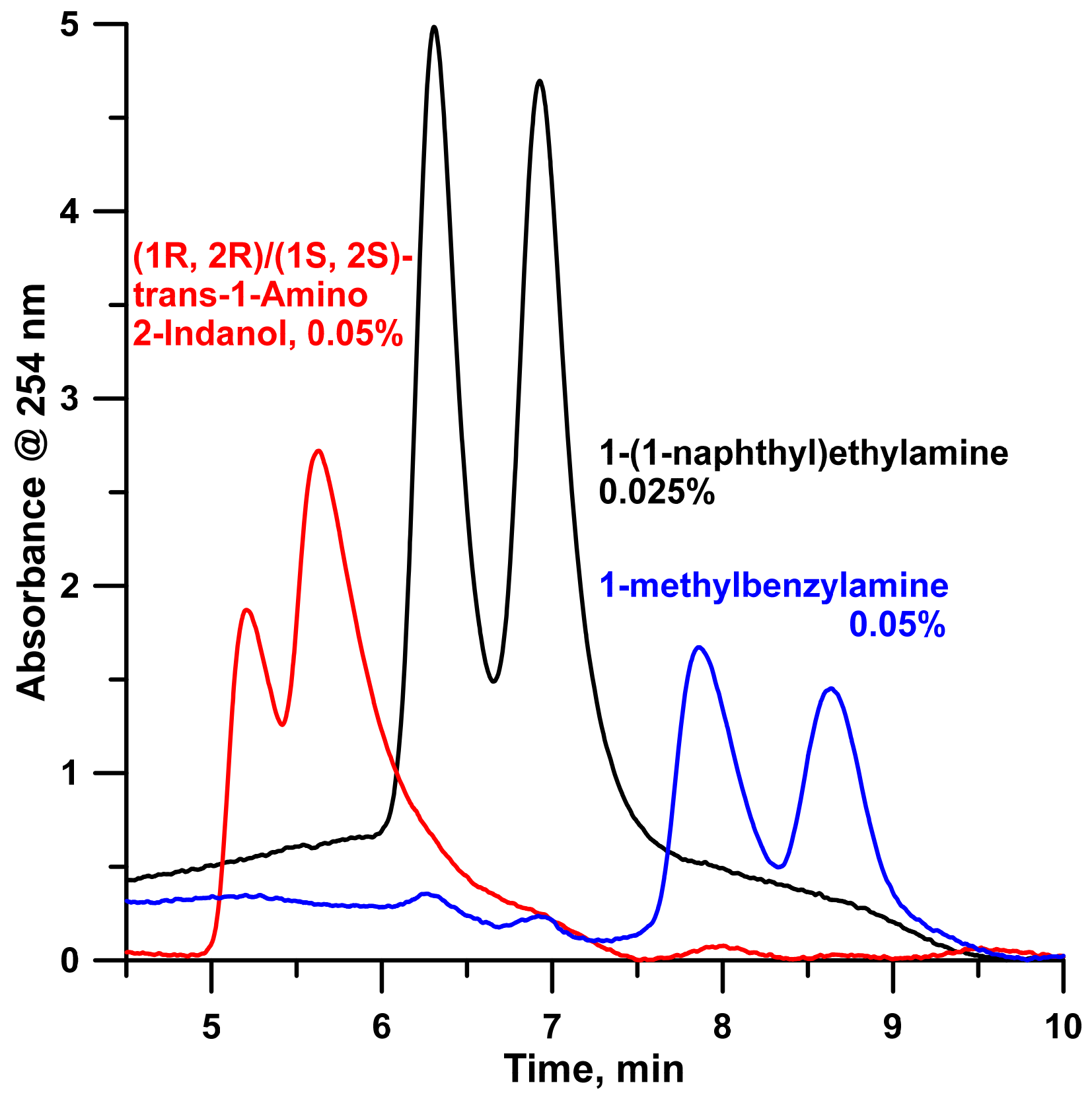

Figure S13. Chiral separation of several racemic primary amines at higher concentrations using a TEA-carbonic acid eluents in 60:40 ACN:MeOH containing $0.05 \%$ TEA and $\mathrm{pCO}_{2}$. 


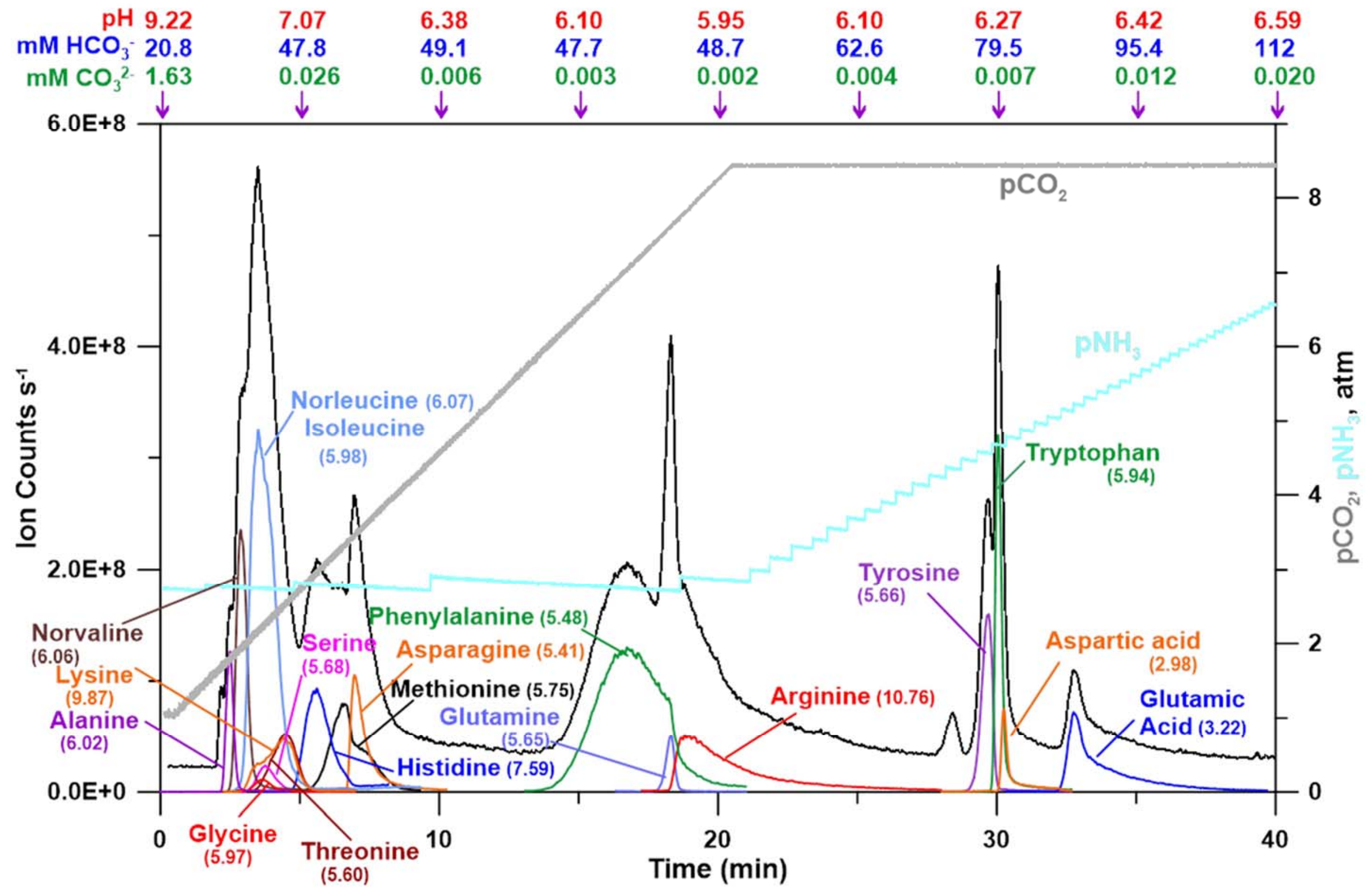

Figure S14. Anion exchange separation of amino acids attempted on a AminoPAC PA10 column set $(2 \times 50 \mathrm{~mm}$ guard $+2 \times 250 \mathrm{~mm}$ separator. Flow rate $0.2 \mathrm{~mL} / \mathrm{min}$ Engassers: $\mathrm{CO}_{2} ; 42 \mathrm{~cm}, \mathrm{NH}_{3}: 25 \mathrm{~cm}$. The black trace is the total ion chromatogram in the positive ion 
mode and the lower traces represent the extracted ion chromatograms corresponding to the $(\mathrm{M}+\mathrm{H})^{+} \mathrm{peaks}$. The $\mathrm{pl}$ values are indicated in parentheses. We did not have the ability in the present configuration to purge/evacuate the $\mathrm{CO}_{2}$ engasser, so when the initial pH was kept with ammonia, $\left[\mathrm{CO}_{3}{ }^{2-}\right]$ was significant. The amino acids elute in three broad groups under these conditions. The first group has the most analytes and except for Lys and His, the pl values all lie between 5.4 and 6.1 at effective pH values between 6.4 and 7 , they are poorly retained. Lys has a high pl and its early elution is understandable. His has a pl somewhat higher than the rest but its retention is promoted by $\pi-\pi$ interaction with the aromatic packing skeleton and the heterocyclic ring. In the second group, GIn is similar to Asn, with the added carbon providing somewhat greater retention. Phe has a pl similar to those in the first group but the aromaticity provides for $\pi-\pi$ interaction. With slightly higher $\mathrm{pK}_{\mathrm{as}}$ and aromaticity (much greater for Trp), Tyr and Trp elute in the third group. The elution of Asp and Glu, the two most acidic analytes in the third group is understandable. We are unable to rationalize the elution of Arg, the most basic analyte, in the second group.

MS Operating Conditions: Spray Voltage $=+1 \mathrm{kV}$, Vaporizer Temperature $=300{ }^{\circ} \mathrm{C}$, Sheath Gas Pressure $=55$, lon Sweep Gas Pressure $=0$, Auxiliary Gas Pressure $=40$, Ion Transfer Capillary Temperature $=350{ }^{\circ} \mathrm{C}$, Skimmer Offset $=0$. Amino acids were detected using Q3 with a resolution of 0.5 by selected ion monitoring. The dwell time for each mass was 10 msec. The following masses were monitored: $76,90,106,116,118,120,122,132,133,134,147,148,150,156,166,175,182,205$. 


\section{Permeative Introduction of Acetic Acid through a Teflon AF Engasser.}

A liquid can also be introduced by permeation through an engasser and the rate of permeation can be controlled by the applied pressure. Temperature is also a useful variable in this case and an increased temperature generally increases the rate of permeation. Either of the systems depicted in Figures S15 or Figure S16 overleaf can be used; majority of the data come from the system in Figure 15.

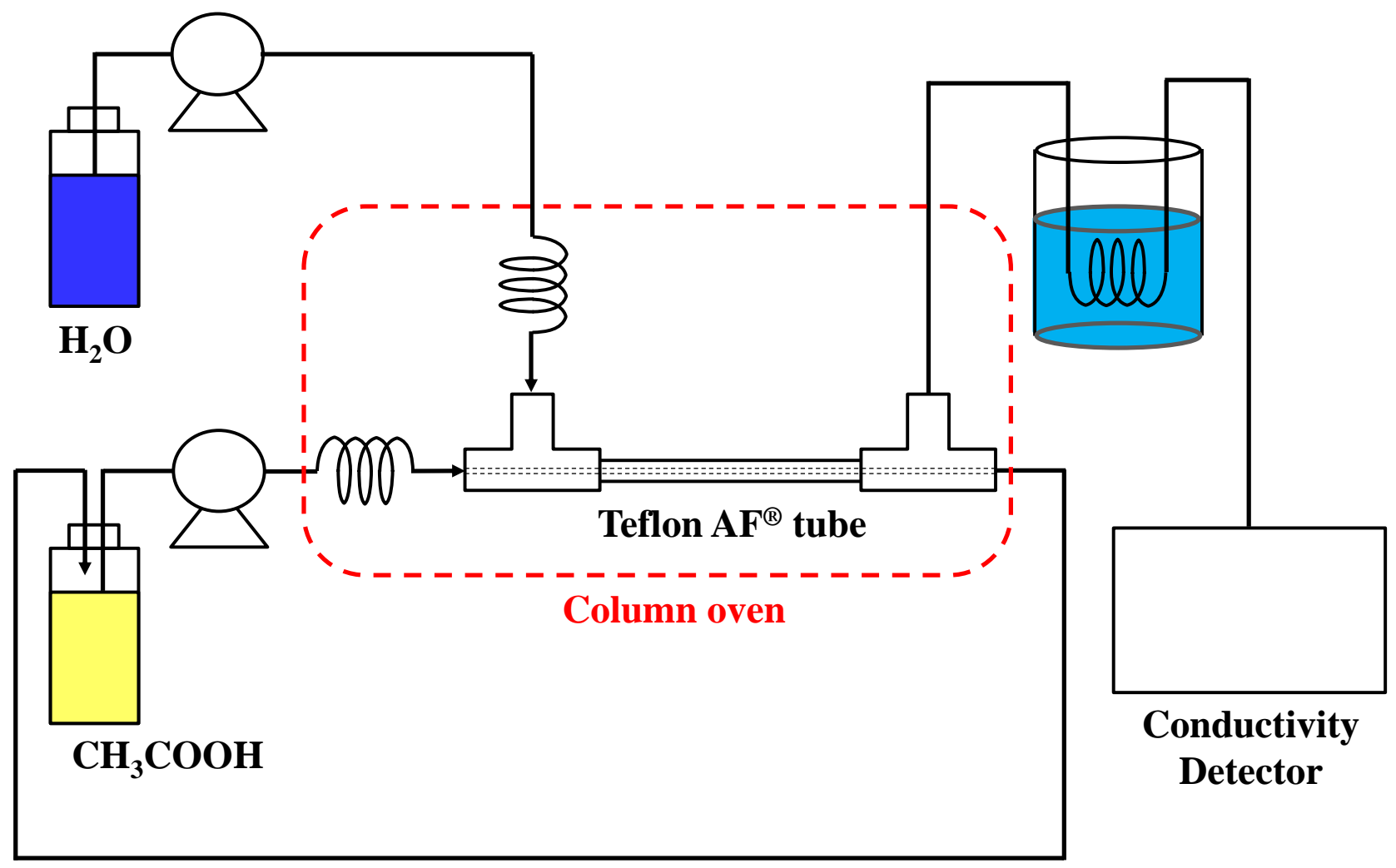

Figure S15. Apparatus for permeation rate determination. Deionized water is pumped by one pump (Dionex Model IS25) at a flow rate of $0.1 \mathrm{~mL} / \mathrm{min}$ through a stainless-steel temperature equilibration coil into the jacket of a 12-cm long Teflon AF (TAF) Capillary based engasser maintained in a temperature-controlled oven indicated schematically by the dashed line enclosure. The jacket effluent travels through another temperature equilibration coil immersed in a water bath designed to bring the temperature down to ambient before the conductivity is measured by a flow-through detector. Specific conductance of $0-2 \mathrm{mM} \mathrm{CH}_{3} \mathrm{COOH}$ standards is premeasured with the detector so measured effluent conductance can be interpreted in terms of $\mathrm{CH}_{3} \mathrm{COOH}$ concentration. A second pump (Dionex model GP40), equipped with a pressure readout, is used to recirculate glacial acetic acid through the lumen of the TAF tube. The primary pressure drop is caused by the Teflon AF tube itself. This varied by changing the recirculation flow rate. The average transmembrane pressure experienced by the TAF membrane is half the pressure readout from the pump, although the latter value is used in the plots that follow. 


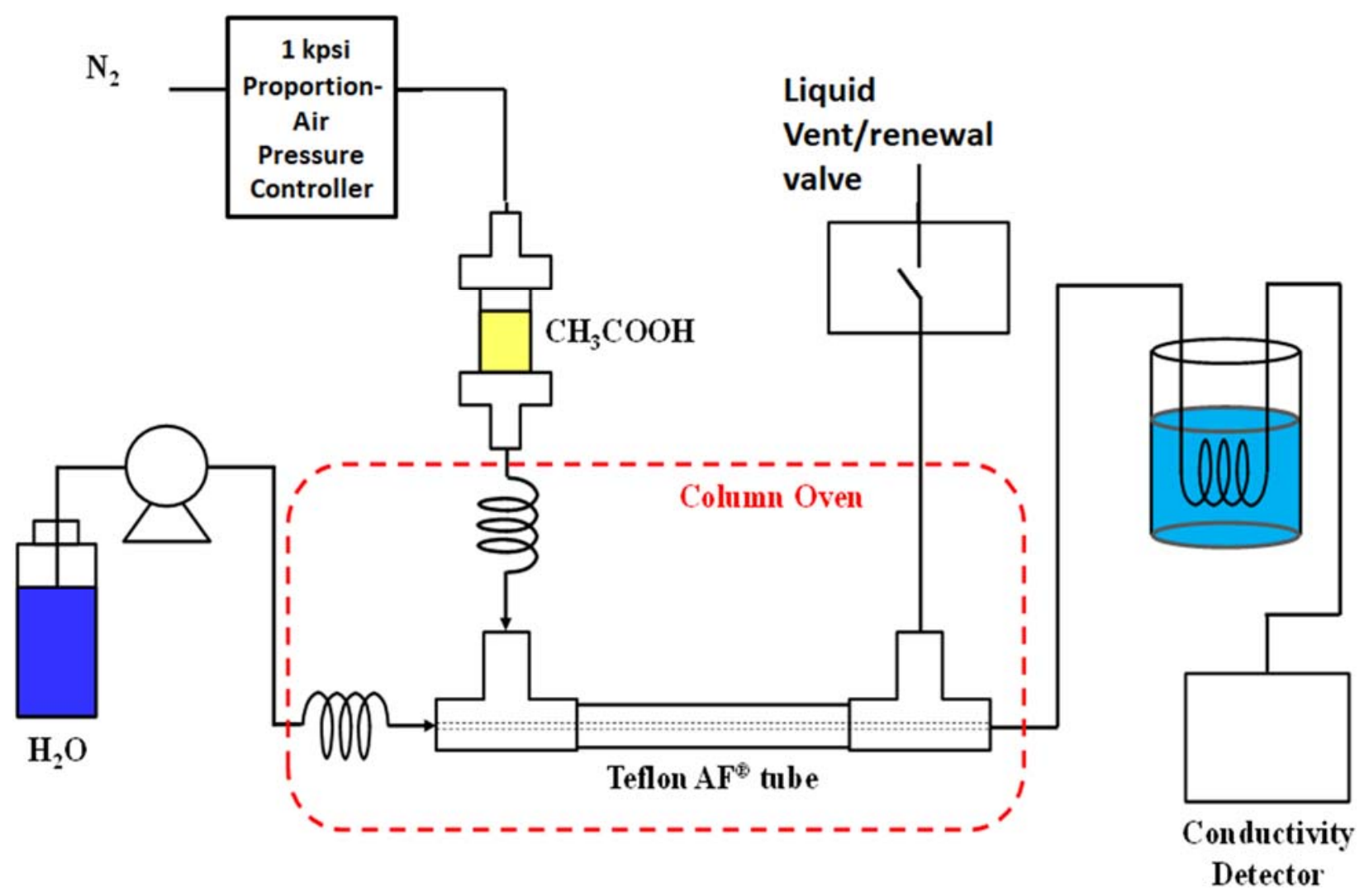

Figure S16. This arrangement differs from that in Figure S15 in that outer jacket now acts as the donor and contains pneumatically pressurized acetic acid. Because there is no flow in the jacket, the entire membrane experiences the same pressure. Although outward permeation of water through Teflon AF is not fast, the total volume in the jacket is low and over a period of time the acid in the jacket will be diluted, especially at the allimportant membrane interface. The donor can be periodically replenished by opening the vent valve or having a capillary restrictor at the jacket exit to maintain a very small flow of the donor liquid. 




Figure S17. Dependence of donor pressure (right ordinate, blue trace), obtained by varying the pumped flow rate in lumen the range of $0.1-1.0 \mathrm{~mL} / \mathrm{min}$ (using the setup in Figure S15) on permeated acetic acid concentration (jacket influent water flow rate 0.1 $\mathrm{mL} / \mathrm{min}$ ). Device temperature $60^{\circ} \mathrm{C}$. 


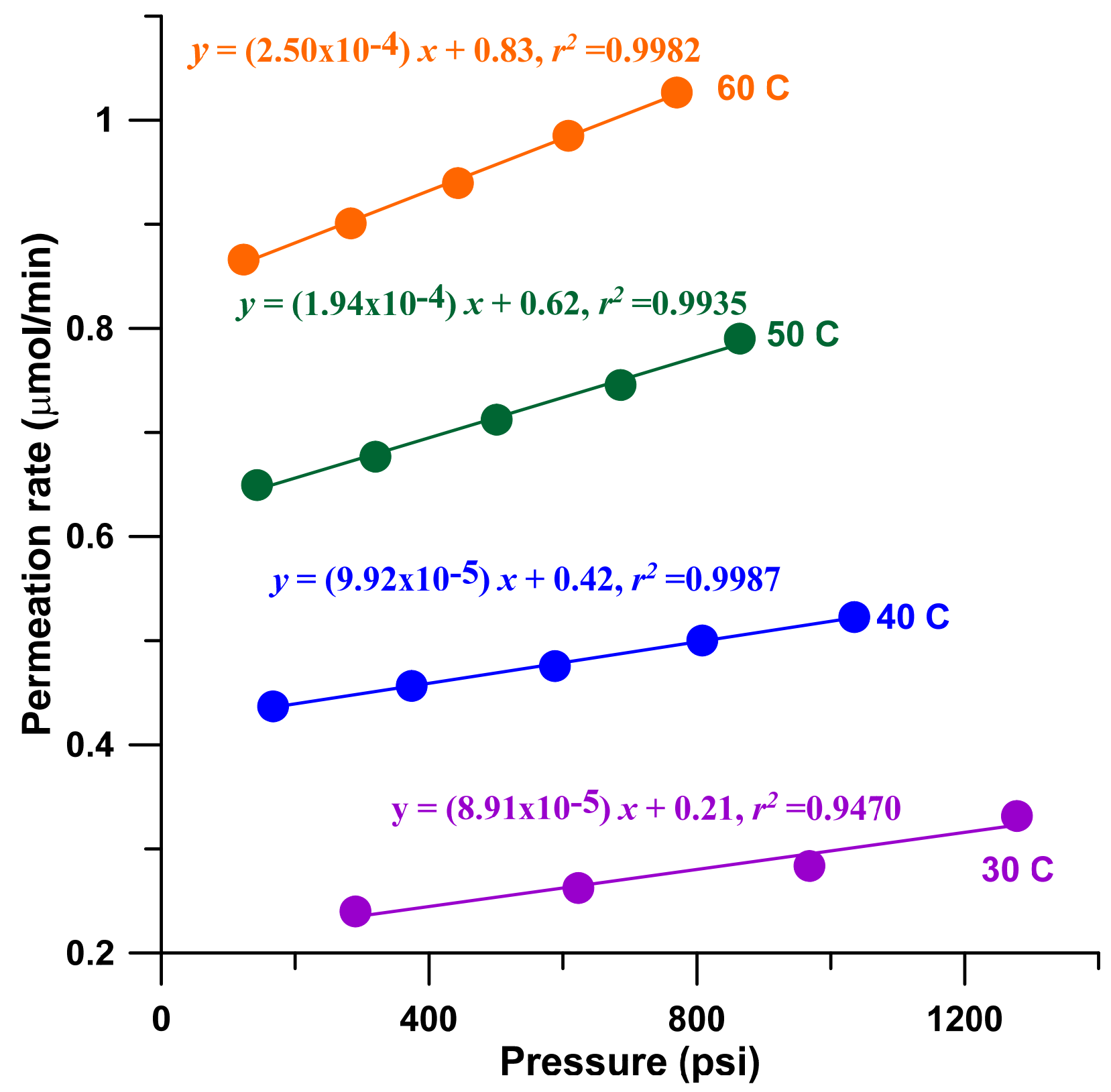

Figure S18. The permeation rate as a function of pressure. All except the $30{ }^{\circ} \mathrm{C}$ data indicate good $\left(r^{2}>0.99\right)$ linear correlation with pressure. An Arrhenius plot of In (slope) vs. reciprocal absolute temperature of the $40-60^{\circ} \mathrm{C}$ data shows reasonable correspondence (linear $r^{2}$ 0.9449) and the resulting linear slope indicates an activation energy of $40.3 \pm 9.7 \mathrm{~kJ}$. 

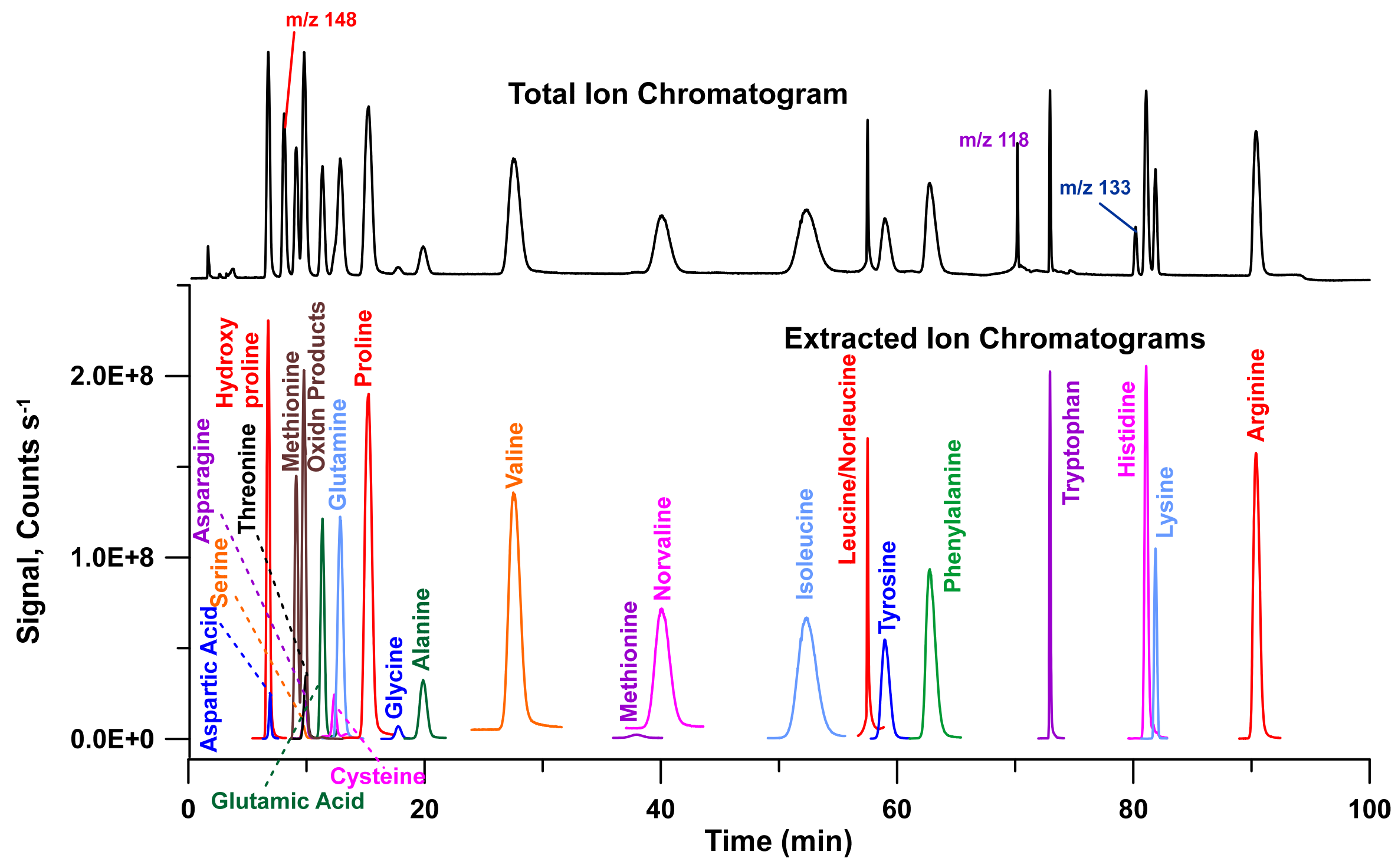

Figure S19. Extracted ion chromatograms in the bottom panel. Same data as Figure 6 . The peaks marked at $\mathrm{m} / \mathrm{z} 148,118$, and 133 were present in the injected amino acid mixture but were not identifiable as an amino acid, are likely degradation products. Methionine, for example, oxidizes relatively rapidly. Original concentrations of each amino acid were $100 \mu \mathrm{M}$ but the thiol bearing amino acids, notably methionine and cysteine were oxidatively lost rather rapidly. Glycine has intrinsically low response, the zwitterion is present even in the gas phase. ${ }^{S 7}$ Mass Spectrometer operating conditions are the same as in Figure S14. 
More on Amino Acid Separation on Hitachi Columns. To our knowledge, the Hitachi amino acid analyzer is the only dedicated commercially available amino acid analyzer that uses essentially exactly the same strategy as the original work of Spackman, Stein and Moore to separate and detect amino acids. Although it does not use the same eluent system, it uses the same styrene-divinylbenzene strongly acidic sulfonate type cation exchanger (albeit in a far more efficient form with $3 \mu \mathrm{m}$ particles) and the same ninhydrin-based postcolumn colorimetric reaction system with dual wavelength detection. A single channel pump is used with step gradients applied with as many as 5 buffers differing in $\mathrm{pH}$ and ionic strength. Depending on whether a fewer number of analytes are to be separated or larger number of analytes are to be separated at the cost of speed, a Na-Citrate or Li-Citrate (+ citric acid) based buffer system is respectively used. Both protocols use multiple changes in column temperature (not a monotonic increase or decrease in temperature) during the run. ${ }^{88}$ The same stationary phase is available in multiple dimensions (both diameter and length); the ones we used were the shortest offered and hence also designated SC (for short column). The columns are offered also in two different designations PH and PF, intended respectively for protein hydrolysate and physiological fluid samples; the latter has higher capacity as the sample is expected to contain a significant amount of indigenous salt.

Some amino acid separation examples on the PF column with the $\mathrm{NH}_{3}-\mathrm{CO}_{2}$ engasserbased eluent separation system follows. In all of the following, the initial influent concentration was a constant $60 \mathrm{mM} \mathrm{AcOH}$. The equipment used included Surveyor LC pump plus, Surveyor Autosampler plus and TSQ QUANTUM Discovery MAX (All from Thermo Fisher Scientific). Mass Spectrometer operating conditions are the same as those in Figure S14. 


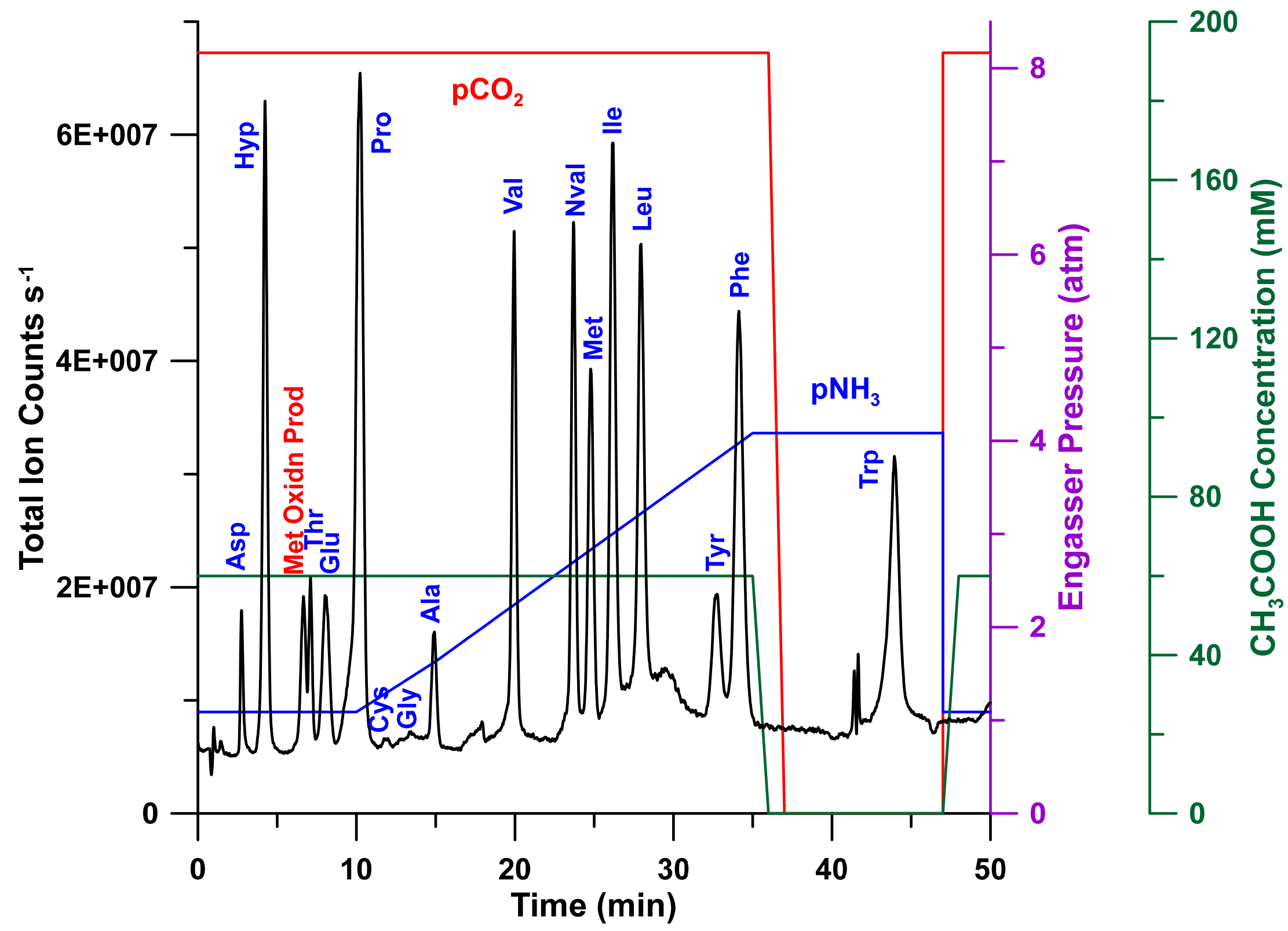

Figure S20. Complete separation of 16 amino acids on a Hitachi 2622SC PF column ( $6 \times 40 \mathrm{~mm}, 3 \mu \mathrm{m}), 0.51 \mathrm{~mL} / \mathrm{min}$, in $\sim 45 \mathrm{~min}$ at 30 ${ }^{\circ} \mathrm{C}$. Standard abbreviations of amino acids ${ }^{\mathrm{S9}}$ are used. $\mathrm{NH}_{3}$ engasser $42 \mathrm{~cm} \mathrm{pNH}$, max $4.08 \mathrm{~atm}, \mathrm{CO}_{2}$ engasser $5.5 \mathrm{~cm}, \mathrm{pCO}_{2 . \max } 8.16$ atm. 


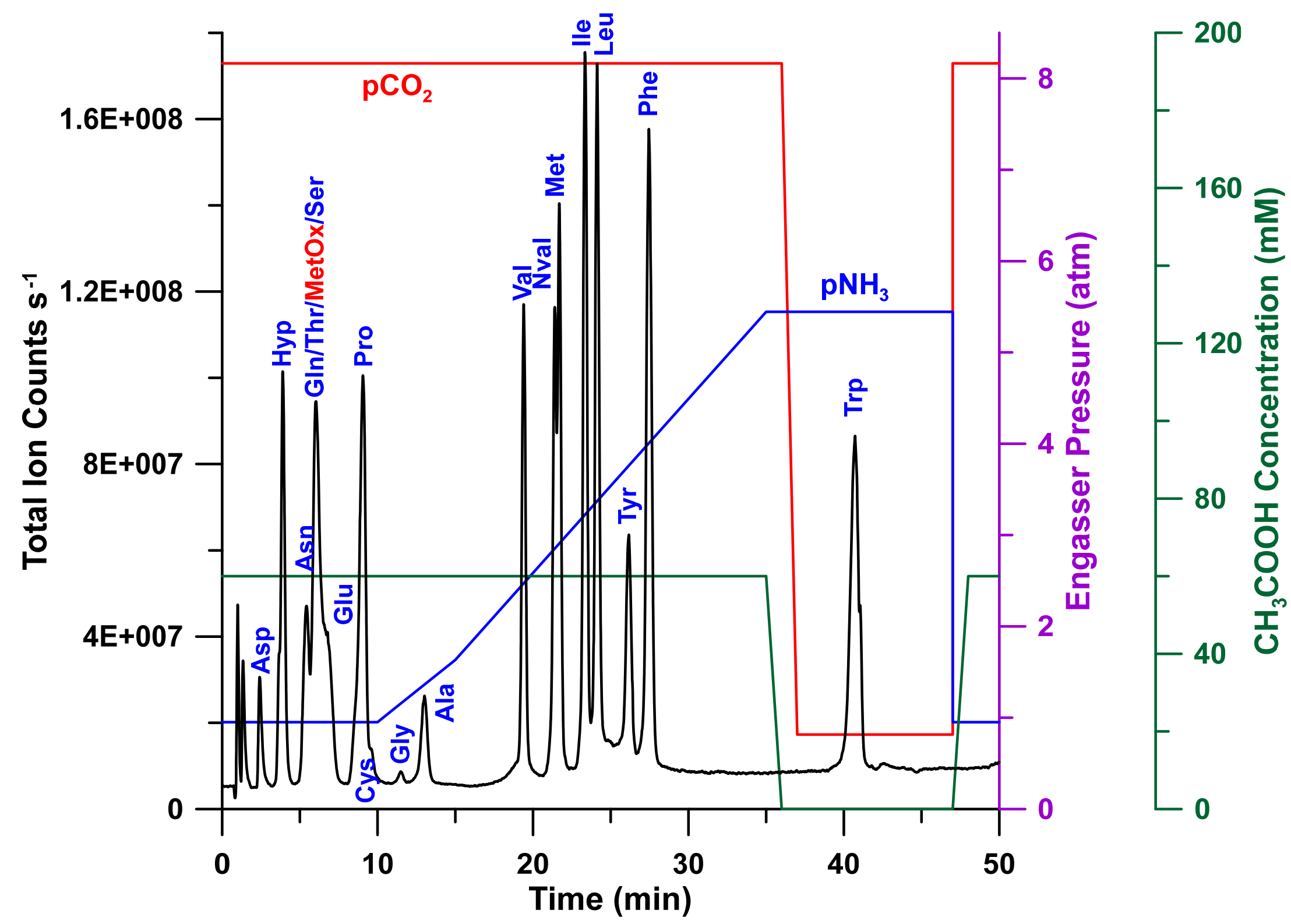

Figure S21. Separation of same amino acids (plus three added: Asn, GIn, Ser, that do not separate well) on the same column at $50{ }^{\circ} \mathrm{C}$. Note that $\mathrm{pNH}_{3}$ is run up to $5.5 \mathrm{~atm}$, compared to $4 \mathrm{~atm}$ in Figure S20. Retention of all analytes decrease. Nval-Met retention order is maintained but whereas these were previously baseline resolved, they can barely be seen apart. All other conditions same as Fig. S20. 


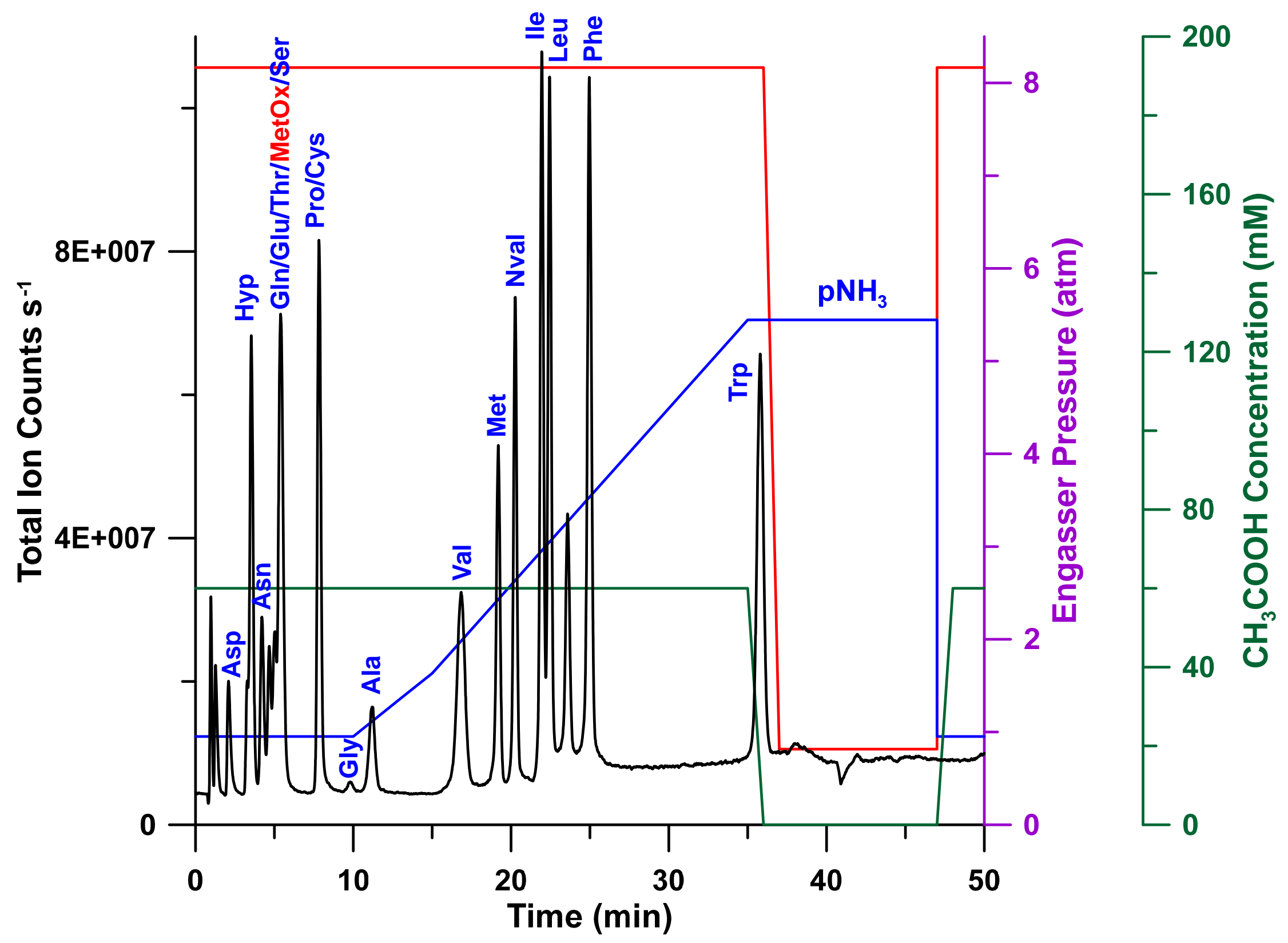

Figure S22. Identical to Figure S21, except at $65^{\circ} \mathrm{C}$. Note entire run is completed by $37 \mathrm{~min}$, Met and Nval are baseline resolved again; now Met elutes before Nval. 


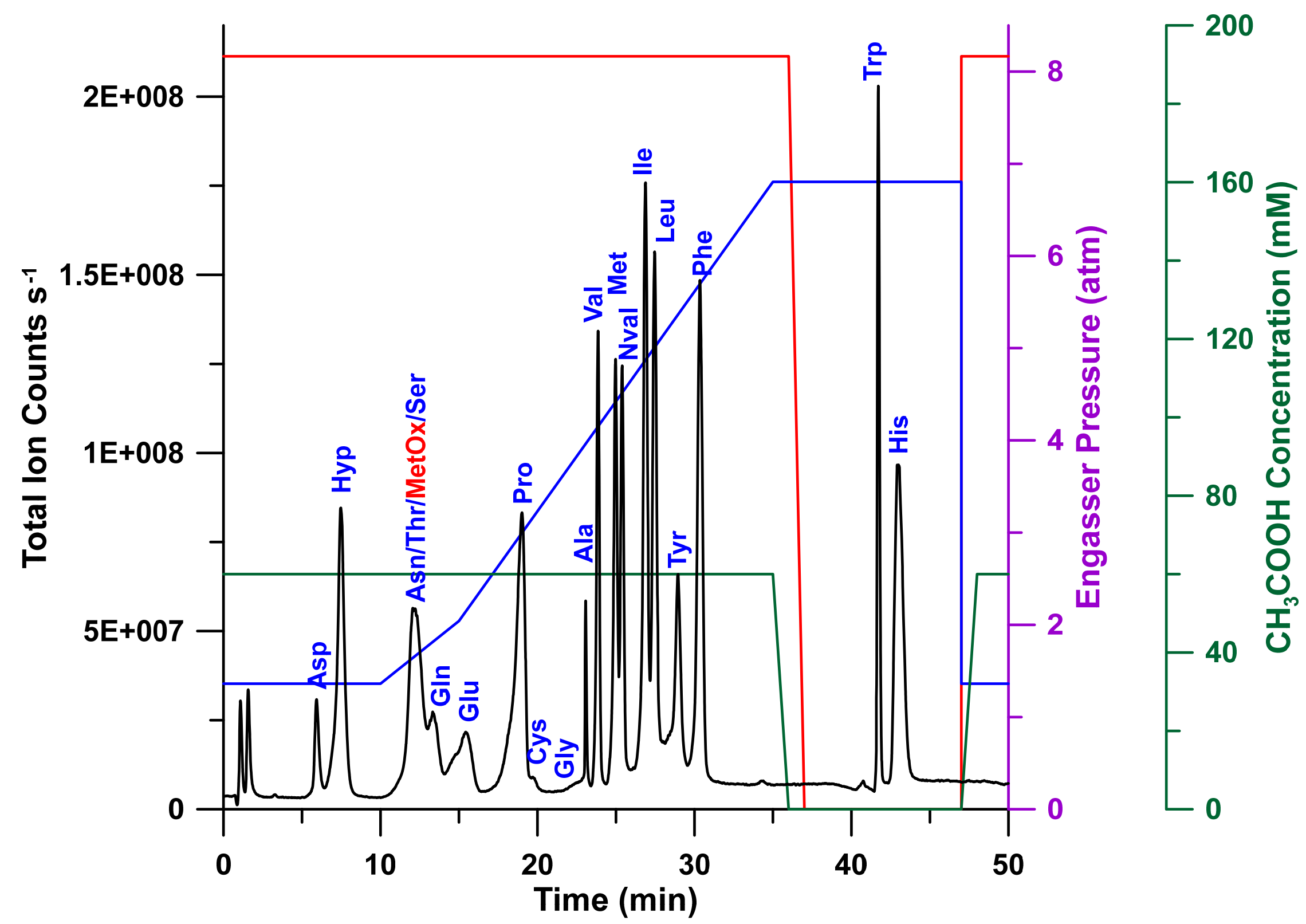

Figure S23. Ammonia pressure is run up to $6.8 \mathrm{~atm}$ in this case. In the latter part of the gradient, $\mathrm{CO}_{2}$ introduction is cut off, acetic acid is changed for water at $\sim 36$ min and high amounts of $\mathrm{NH}_{3}$ are introduced making for an alkaline eluent and allowing histidine to be eluted. Although all amino acids were detected within $50 \mathrm{~min}$, Asn, Thr and Ser co-elute. Other conditions same as Figure S20. 
Table S2. Enthalpy of Partition for Selected Amino Acids Calculated for Elution Conditions used in Figures $\mathrm{S} 21$ and $\mathrm{S} 22, t=30-70^{\circ} \mathrm{C}$

\begin{tabular}{|c|c|}
\hline Amino Acid & $\Delta \mathbf{H}^{\mathbf{0}}, \mathbf{k J} / \mathbf{m o l}$ \\
\hline Asp & -13.9 \\
\hline Hyp & -8.6 \\
\hline Asn & -18.5 \\
\hline gly & -10.5 \\
\hline Ala & -9.5 \\
\hline Val & -8.9 \\
\hline Met & -7.8 \\
\hline Nval & -3.4 \\
\hline Ile & -3.9 \\
\hline Leu & -4.6 \\
\hline Tyr & -6.6 \\
\hline Phe & -6.0 \\
\hline Trp & -7.9 \\
\hline
\end{tabular}

In general, the enthalpies increase with decreasing retention but increase again for the late eluting aromatic amino acids. 


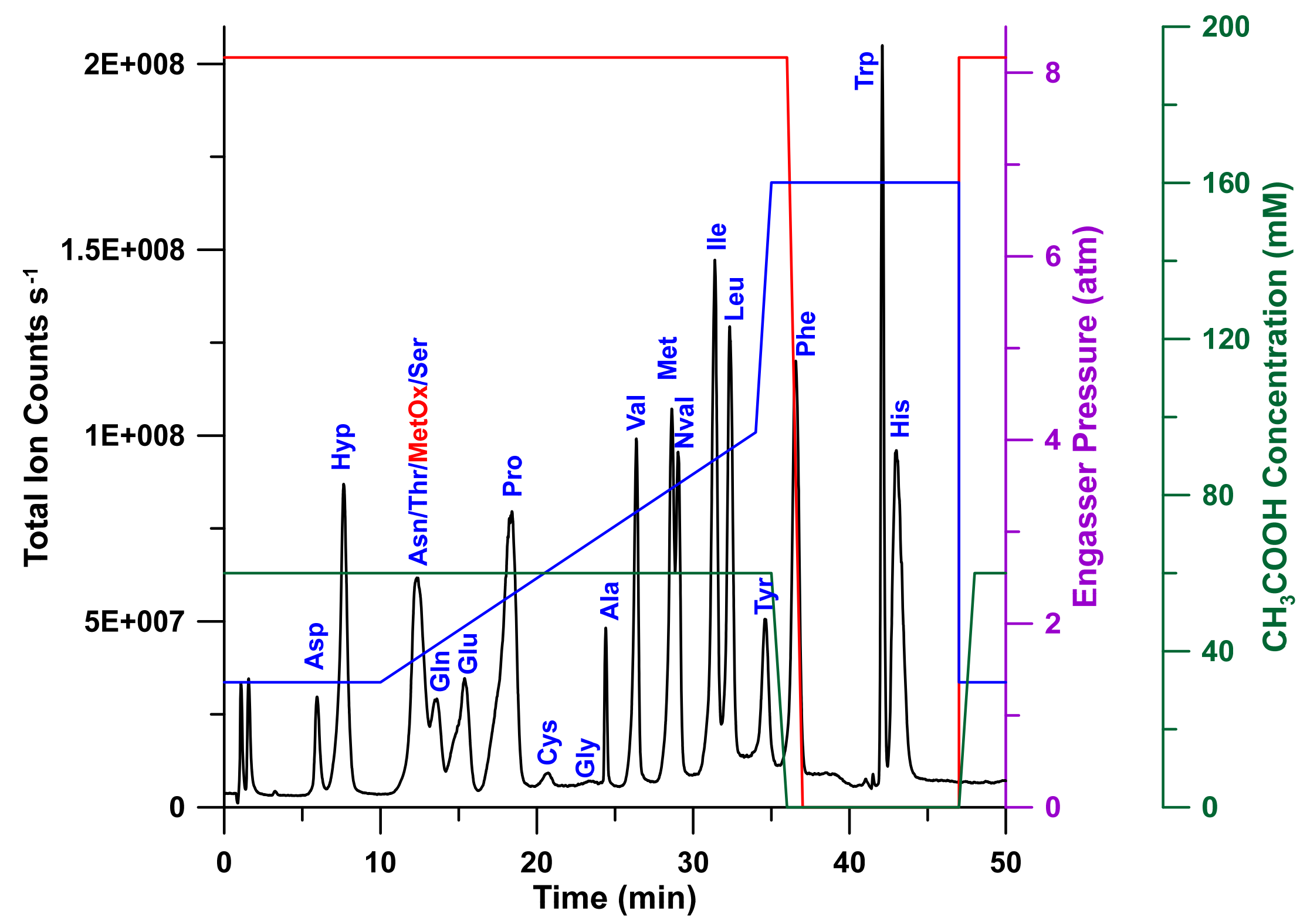

Figure S24. The analytes in the 20 to 30 min window in Figure S23 eluted relatively close to each other. A 2-step gradient in $\mathrm{pNH}_{3}$, is used. Based on the enthalpy data, the temperature was changed from 30 to 65 degree at $15 \mathrm{~min}$, and back to 30 degree at $40 \mathrm{~min}$. All amino acids except Asn, Thr and Ser were separated, the resolution in the 20-30 min window improved. Other conditions same as Figure S20. 


\section{Retention Constancy as a Function of Loading}

The separation of the acidic ( $\mathrm{pl} \mathrm{6.8)}$ ) and basic ( $\mathrm{pl} 7.2$ ) versions of myoglobin was studied with two different eluents. For separations by capillary isoelectric focusing of the two, see ref, S10. The total flow rate was $0.15 \mathrm{~mL} / \mathrm{min}$ with the flow split $3: 1$ via the $\mathrm{CO}_{2}$ and $\mathrm{NH}_{3}$ engassers, respectively before recombining. Both eluents were generated with $5.5 \mathrm{~cm}$ long engassers each for $\mathrm{CO}_{2}$ and $\mathrm{NH}_{3}$. The first eluent utilized $15.3 \mathrm{~atm}$. $\mathrm{pCO}_{2}$ and $5.1 \mathrm{~atm} \mathrm{pNH}_{3}$ while the second eluent used $6.1 \mathrm{~atm} \mathrm{pCO}_{2}+3.4 \mathrm{~atm} \mathrm{pNH}_{3}$. These respectively produced a higher ionic strength lower $\mathrm{pH}$ eluent (measured specific conductance $3.706 \mathrm{mS} / \mathrm{cm}$, measured $\mathrm{pH}$ 6.12) and a lower ionic strength higher $\mathrm{pH}$ eluent (measured specific conductance $2.436 \mathrm{mS} / \mathrm{cm}$, measured pH 6.44, both at 30 ${ }^{\circ} \mathrm{C}$ ). These $\mathrm{pH}$ values were near the $\mathrm{pl}$ values where the exact retention factor will be the most susceptible to variations in $\mathrm{pH}$, whether due to lack of system control or affected by sample loading. As observed in Figure S25, there was no systematic change in retention with sample loading.

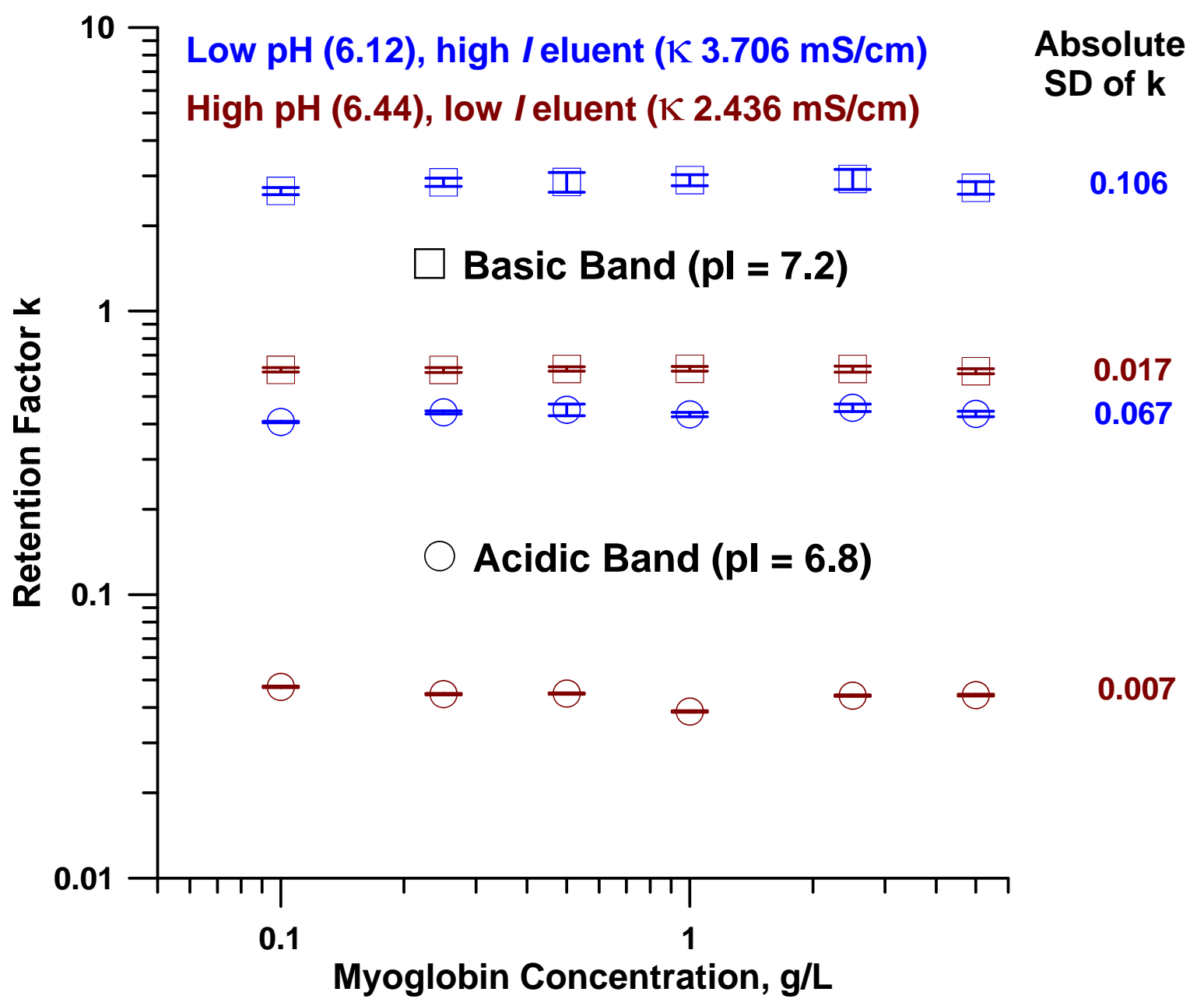

Figure S25. The retention of both acidic and basic band of myoglobin was reproducible and essentially independent of loading over a 50 -fold range of injected concentration ( $5 \mu \mathrm{L}$ injected) for two different generated eluents. 


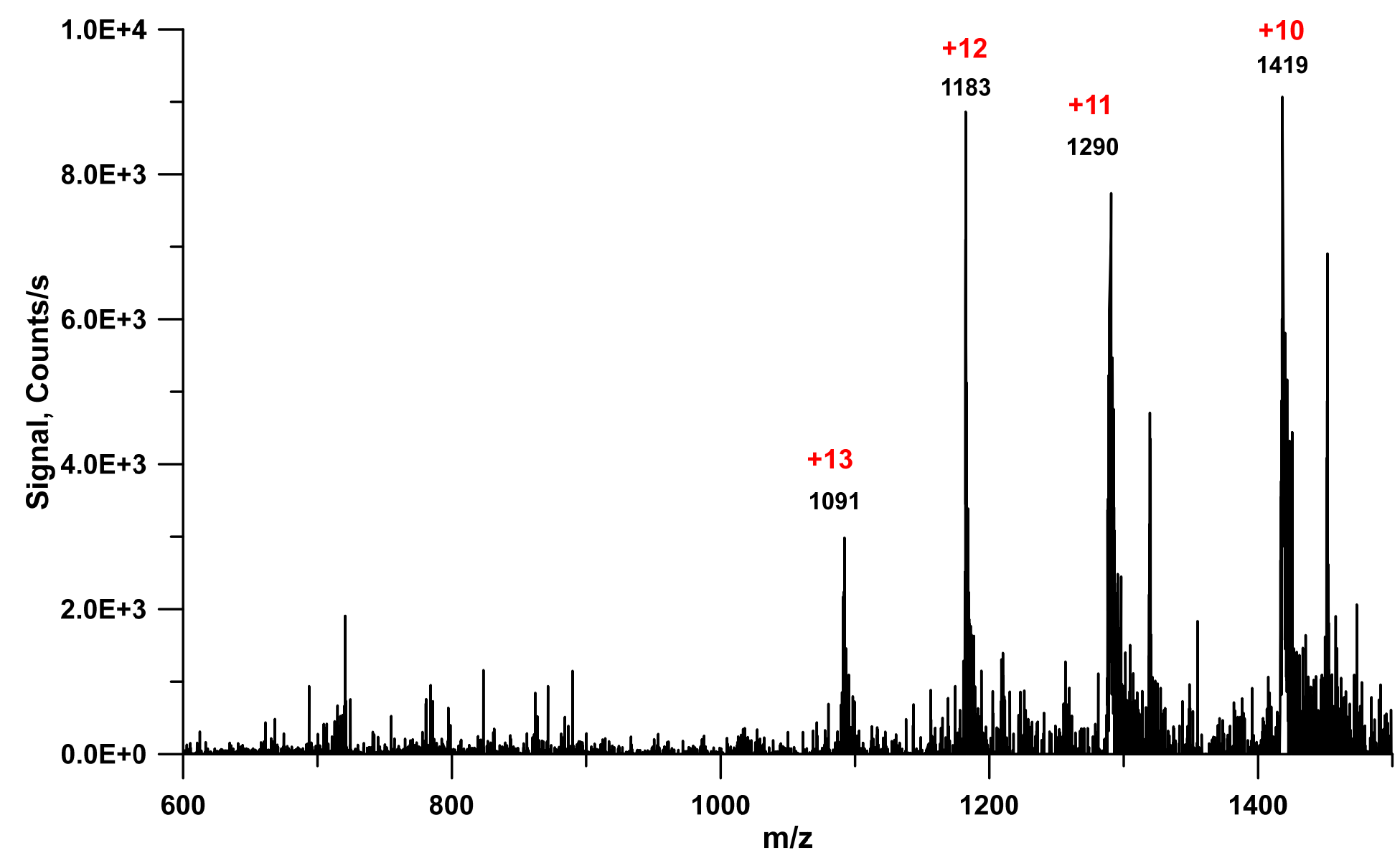

Figure S26. Mass Spectrum for Lactalbumin (obtained at $t=18.03 \mathrm{~min}$ in Figure 9) In the present system. In comparison, the most abundant peak in the literature ESI-mass spectrum (Figure 2, ref.S11) occurs at $\mathrm{m} / \mathrm{z} 2026.382$, designated (M + $\left.7 \mathrm{H}^{+}\right)^{7+}$. The most abundant peak in the present system $(\mathrm{m} / \mathrm{z} 1419$, charge state +10$)$ is the lowest $\mathrm{m} / \mathrm{z}$ peak marked in the cited reference, albeit the $\mathrm{m} / \mathrm{z} 1290$ peak can be barely seen. As the overall $\mathrm{S} / \mathrm{N}$ is poor in this spectrum, we refrain from overinterpretation. Operating Conditions: Spray Voltage $=+5 \mathrm{kV}$, Vaporizer Temperature $=25^{\circ} \mathrm{C}$, Sheath Gas Pressure $=$ 45, Ion Sweep Gas Pressure $=0$, Auxiliary Gas Pressure $=40$, Ion Transfer Capillary Temperature $=250{ }^{\circ} \mathrm{C}$, Skimmer Offset $=0$. Detection was performed using Q3 with a resolution of 0.7 FWHM scanning from m/z 500-1500 every 2 seconds. 


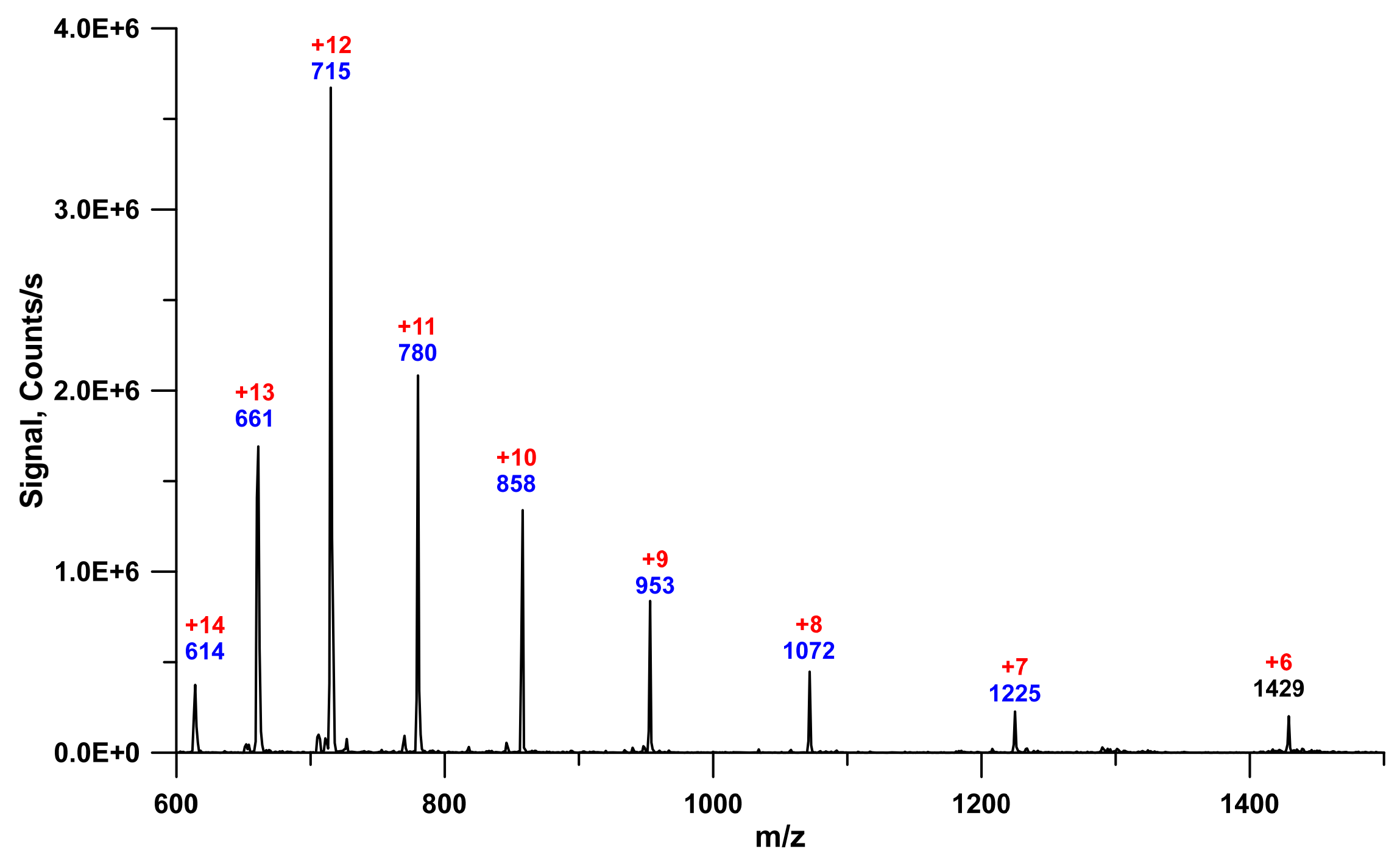

Figure S27. Mass spectrum of ubiquitin (obtained at $t=25.4 \mathrm{~min}$, Figure 9 ). Babu et al. ${ }^{\mathrm{S} 12}$ have previously studied the ESI-mass spectrum of ubiquitin at a pH of 2 with $0,30,35$, and $60 \% \mathrm{v} / \mathrm{v}$ methanol added. The dominant charge state is +5 in $0-35 \% \mathrm{MeOH}$. The +10 state first shows up when methanol is added, increases in intensity between 30 and $35 \%$ $\mathrm{MeOH}$ and becomes the dominant state in $60 \% \mathrm{MeOH}$. In the present case, the dominant charge state is +12 . 


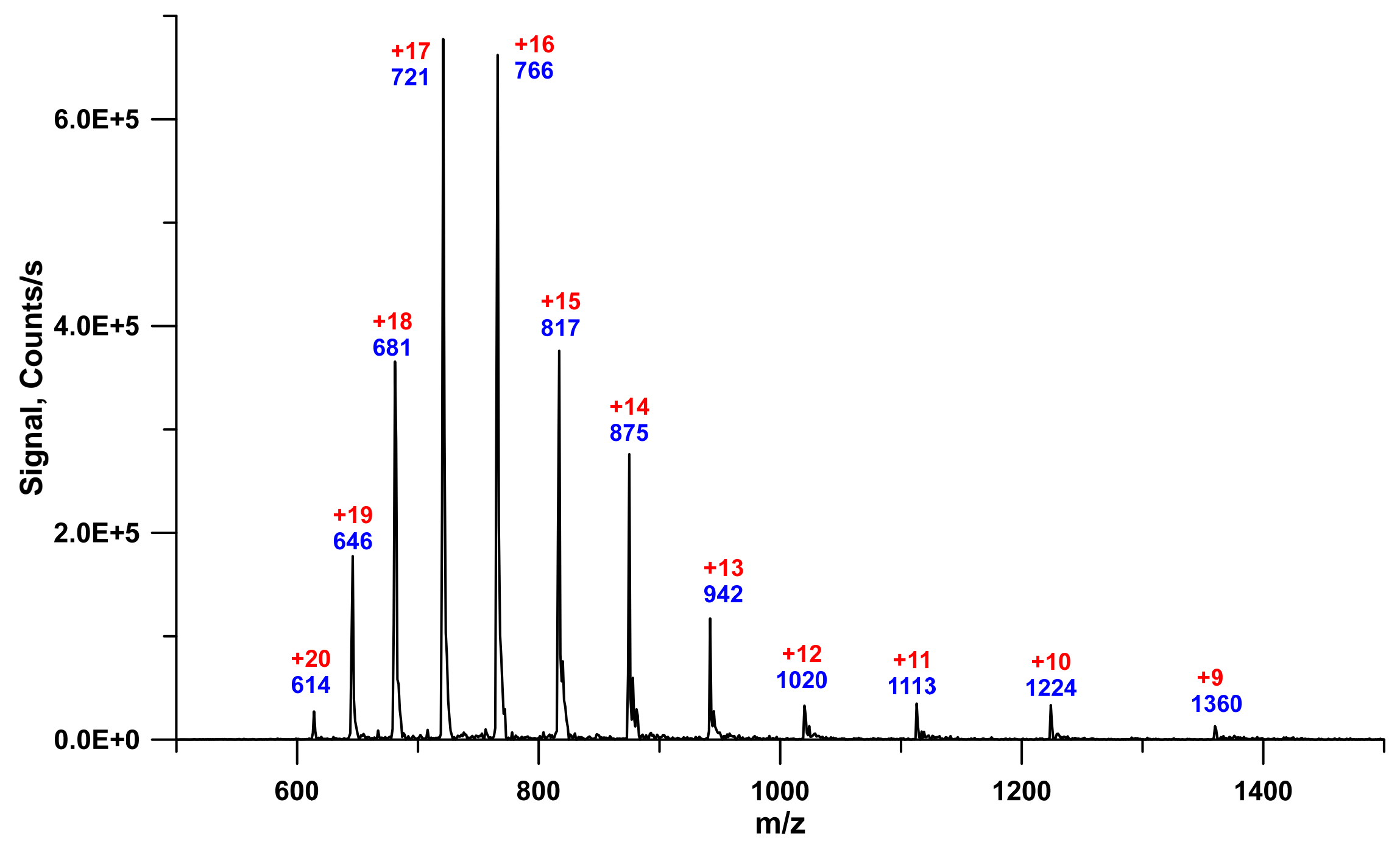

Figure S28. Mass spectrum of bovine cytochrome c (obtained at $t=63.4 \mathrm{~min}$, Figure 9 ). We were unable to readily locate an ESI-mass spectrum that could be readily compared. Most available spectra are obtained under conditions that has sufficient organic solvent, often with significant amount of added acid, such that unfolding may have already occurred, see e.g., ref. S13. 


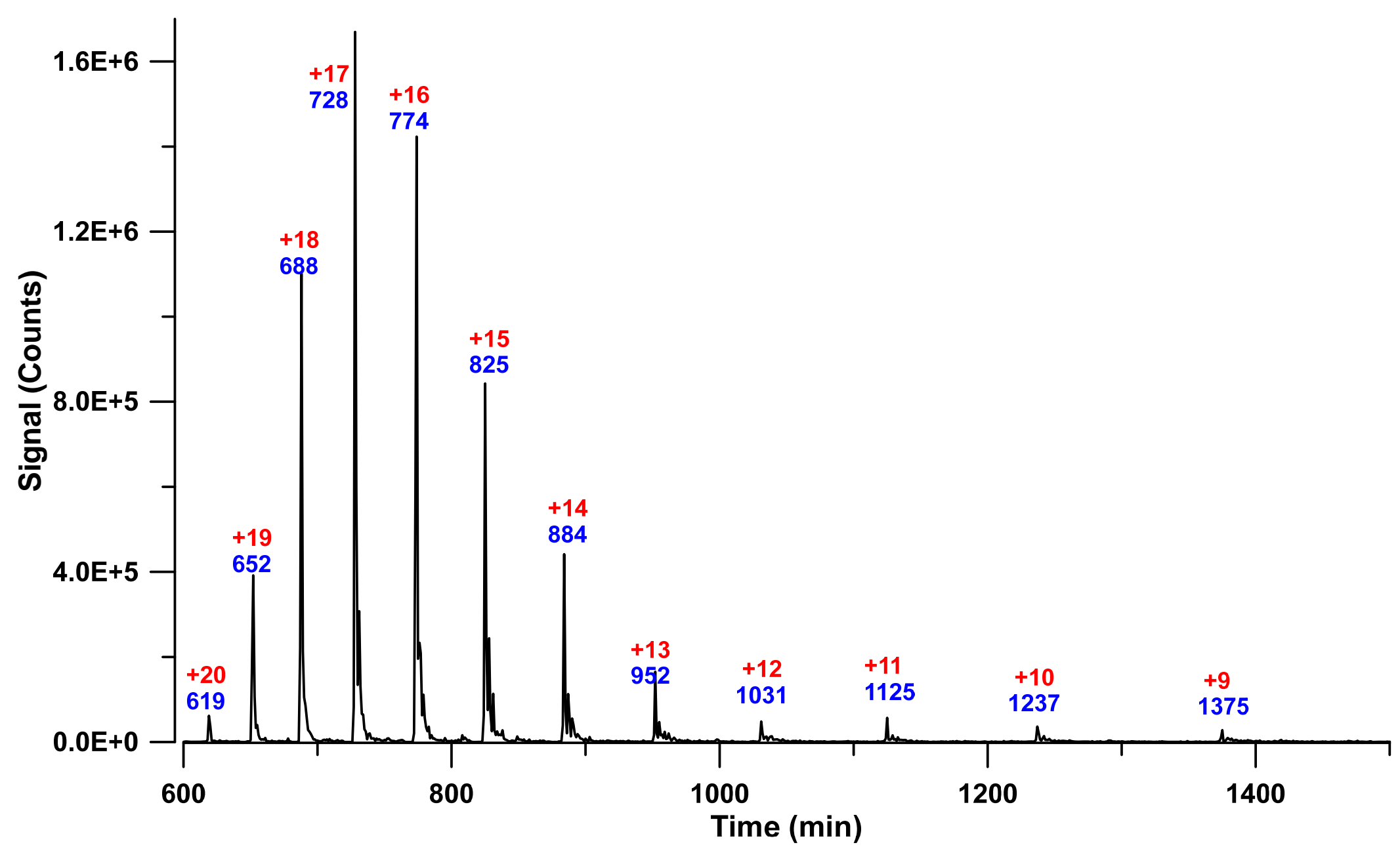

Figure S29. Mass Spectrum of equine cytochrome c (obtained at $t=67.7 \mathrm{~min}$, Figure 9). Konerman and Douglas ${ }^{\mathrm{S} 14}$ monitored the ESI-MS spectra of equine cytochrome $\mathrm{c}$ as a function of methanol content and $\mathrm{pH}$ and attributed changes to unfolding of the protein and changes in tertiary structure. They presented data in $3 \%$ methanol at $\mathrm{pH}$ levels ranging from 6.4 to 2.3. At the highest $\mathrm{pH}$, which will be the closest to the present situation only $+7-+9$ charge states were visible. Even at $\mathrm{pH} 4.2,+9$ was the dominant charge state. Only by $\mathrm{pH} 2.6+17$ became the dominant state and remained so at $\mathrm{pH} 2.3$. 


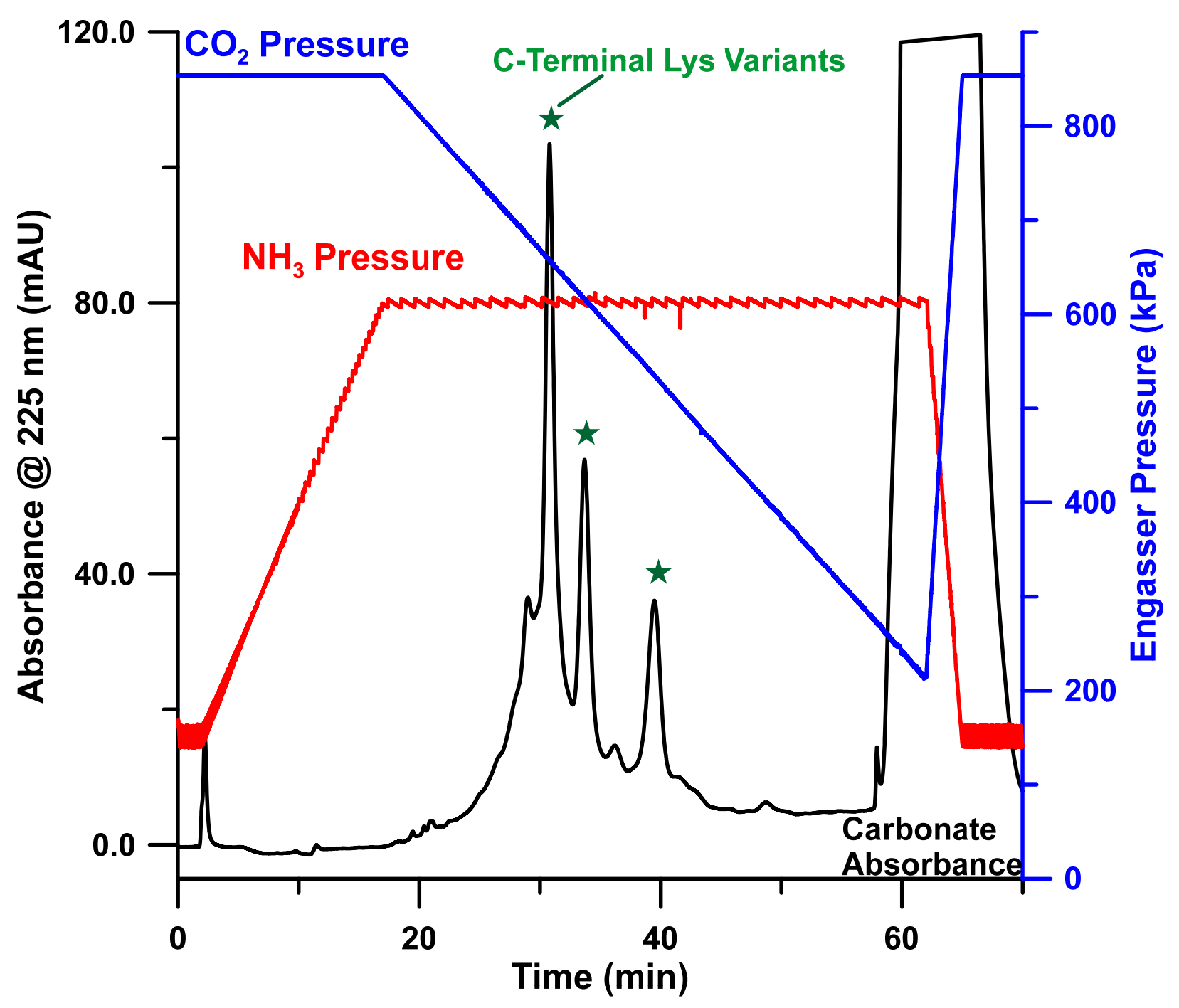

Figure S30. Entire chromatogram and gradient profile for bottom panel of Figure 11. A DionexPDA-100 detector was used. Note that by about $57 \mathrm{~min}$, the eluent becomes significantly alkaline for appreciable concentrations of carbonate, which absorbs strongly at $225 \mathrm{~nm}$. 


\section{REFERENCES}

(S1) Sander, R. Compilation of Henry's Law Constants (version 4.0) for Water as Solvent, Atmos. Chem. Phys. 2015, 15, $4399-4981$.

(S2) Dasgupta, P. K.; Dong, S. Solubility of Ammonia in Liquid Water and Generation of Trace Levels of Standard Gaseous Ammonia. Atmos. Environ.1986, 20, 565-570.

(S3) Read, A.J., 1975. The First lonization Constant of Carbonic acid from 25 to $250^{\circ} \mathrm{C}$ and to 2000 bar. J. Solution Chem. 1975, 4, 53-70.

(S4) Stumm, W. Morgan, J. J. Aquatic Chemistry, Wiley, $2^{\text {nd }}$ ed., 198.

(S5) Emerson K.; Russo R. C.; Land R. E.; Thurston R. V. Aqueous Ammonia Equilibrium Calculations:

Effect of $\mathrm{pH}$ and Temperature. J. Fish. Res. Bd. Can. 1975, 32, 2379-2383.

(S6) Shedlovsky, T. An Equation for Electrolytic Conductance. J. Amer. Chem. Soc. 1932, 54,1405-1411.

(S7) Clyde, D. D.; Svec, H. Vapor Pressures of Some Amino Acids. lowa State University. Research and Development Report IS-790. US Atomic Energy Commission, January 1, 1964.

https://lib.dr.iastate.edu/cgi/viewcontent.cgi?article=1052\&context=ameslab isreports

(S8) Ito, M. Narimatsu, I.; Pei, M.; Morisaki, A.; Suzuki, H. Fukuda, M.; Yagi, T.; Otsuki, S.; Seki, K.;

Toyosaki, K. Model LA8080 High-Speed Amino Acid Analyzer. https://www.hitachi-

hightech.com/global/sinews/technical explanation/110303/ Accessed December 1, 2020.

(S9) International Union of Pure and Applied Chemistry, Nomenclature and Symbolism for

Amino Acids and Peptides. Pure Appl. Chem. 1984, 56, 595-624.

(S10) Mohan, D.; Lee, C. S., Extension of Separation Range in Capillary Isoelectric Focusing for Resolving Highly Basic Biomolecules. J. Chromatogr. A 2002, 979, 271-276.

(S11) Kleinnijenhuis, A. J.; van Gool, M. P.; van Holthoon, F. L.; van den Noort, M.; Huppertz, T. Quantification of Bovine a-Lactalbumin in Infant Milk Formula Using LC-MS. Int. Dairy J. 2021,113, Art.104899.

(S12) Babu, K. R.; Moradian, A.; Douglas, D. J. The Methanol-Induced conformational Transitions of $\beta$ Lactoglobulin, Cytochrome c, and Ubiquitin at Low pH: A Study by Electrospray lonization Mass Spectrometry. J. Am. Soc. Mass Spectrom. 2001, 12, 317-328.

(S13) Wang, E. H.; Nagarajan, Y.; Carroll, F.; Schug, K. A. Reversed-phase Separation Parameters for Intact Proteins using Liquid Chromatography with Triple Quadrupole Mass Spectrometry. J. Sep. Sci.

2016, 39, 3716-3727.

(S14) Konerman, L.; Douglas, D. J. Acid-Induced Unfolding of Cytochrome c at Different Methanol Concentrations: Electrospray Ionization Mass Spectrometry Specifically Monitors Changes in the Tertiary Structure. Biochemistry 1997, 36, 12,296-12,302 